UNIVERSIDAD AUTÓNOMA METROPOLITANA IZTAPALAPA

DIVISIÓN DE CIENCIAS BIOLÓGICAS Y DE LA SALUD

POSGRADO EN BIOLOGÍA EXPERIMENTAL

Efecto del Factor de Crecimiento de Hepatocitos en una línea celular de

páncreas

TESIS

QUE PARA OBTENER EL GRADO DE MAESTRA EN BIOLOGÍA

EXPERIMENTAL

PRESENTA

MAYREL PALESTINO DOMÍNGUEZ

DIRECTOR

DR. LUIS ENRIQUE GÓMEZ QUIROZ

ASESORAS

DRA. MARÍA CONCEPCIÓN GUTIÉRREZ RUIZ

DRA. MARCIA HIRIART URDANIVIA

25 DE AGOSTO DEL 2014 



\title{
COMITÉ TUTORAL
}

\author{
Director \\ Dr. Luis Enrique Gómez Quiroz \\ Universidad Autónoma Metropolitana Iztapalapa \\ Departamento de Ciencias de la Salud, Laboratorio de Fisiología Celular \\ legq@xanum.uam.mx
}

\begin{abstract}
Asesoras
Dra. María Concepción Gutiérrez Ruiz

Universidad Autónoma Metropolitana Iztapalapa

Departamento de Ciencias de la Salud, Laboratorio de Fisiología Celular mcgr@xanum.uam.mx
\end{abstract}

\author{
Dra. Marcia Hiriart Urdanivia \\ Universidad Nacional Autónoma de México \\ Directora del Instituto de Fisiología Celular (IFC) \\ mhiriart@ifc.unam.mx
}


"El Programa de Maestría en Biología Experimental de la Universidad Autónoma Metropolitana pertenece al Programa Nacional de Posgrados de Calidad (PNPC) del CONACYT, registro 001481, en el Nivel Consolidado, y cuenta con apoyo del mismo Consejo, clave DAFCYT-2003IMPTNNN0020".

Número de registro de la beca otorgada por CONACYT a Mayrel Palestino Domínguez: 469704 
La investigación presentada en esta tesis se desarrolló en el Laboratorio de Fisiología Celular del Departamento de Ciencias de la Salud, DCBS, de la Universidad Autónoma Metropolitana Iztapalapa, y en el Departamento de Medicina I de la Universidad Johannes Gutenberg en Mainz Alemania. Contó con financiamiento de Conacyt con número de proyecto 131707 siendo responsable técnico el Dr. Luis E Gómez Quiroz, así como de PROMEP 91302614612111 y de la propia Universidad 
El jurado designado por la Comisión Académica del Posgrado en Biología Experimental de la División de Ciencias Biológicas y de la Salud de la Universidad Autónoma Metropolitana aprobó la Tesis titulada:

"Efecto del factor de crecimiento de hepatocitos en una línea celular de páncreas", que presentó

\section{Mayrel Palestino Domínguez}

El día 25 de agosto del año 2014

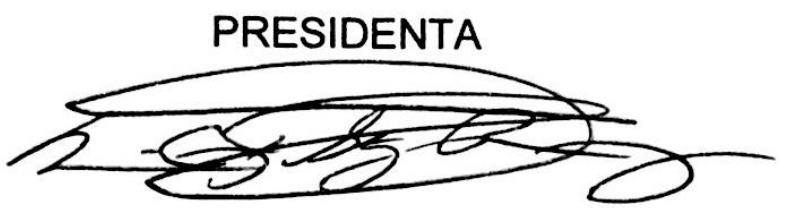

Dra. María Concepción Gutiérrez Ruiz
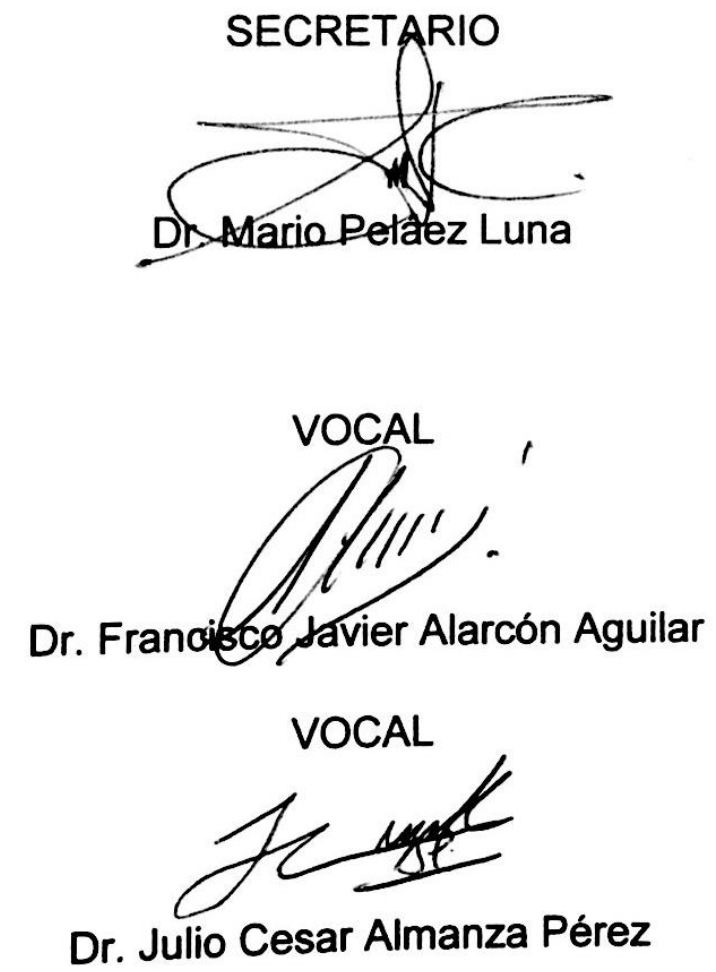


\section{Índice}

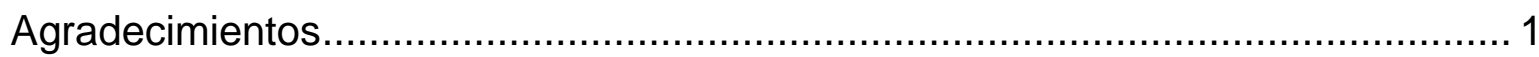

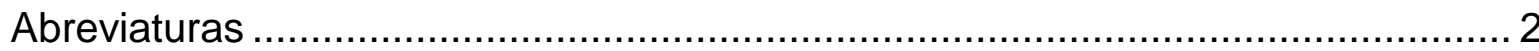

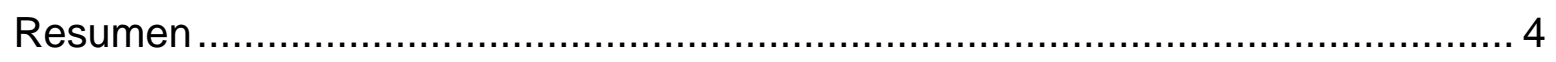

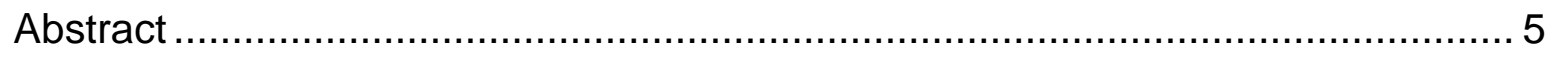

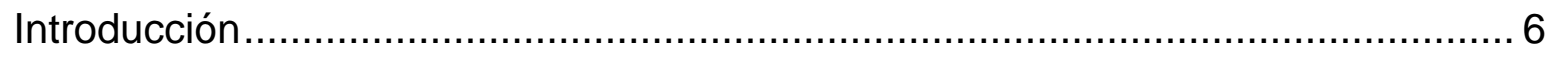

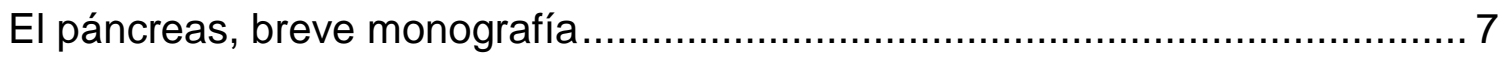

Principales agentes de daño al páncreas ................................................... 7

El etanol y su metabolito el acetaldehído ................................................ 8

El estado redox celular y el estrés oxidante.................................................... 10

Factores de crecimiento y la protección celular ............................................... 14

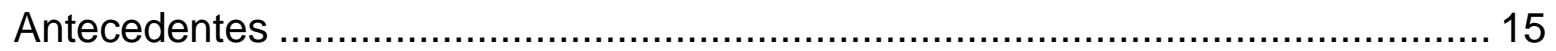

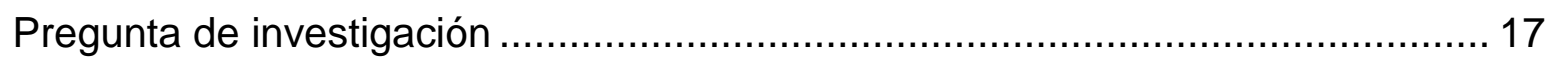

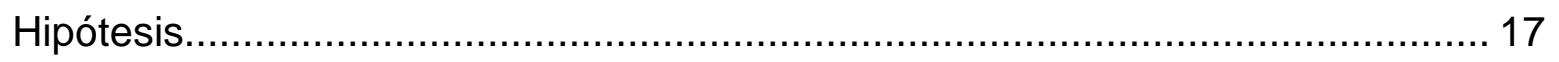

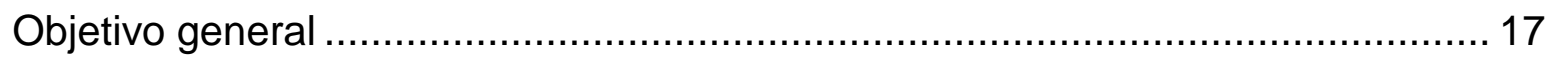

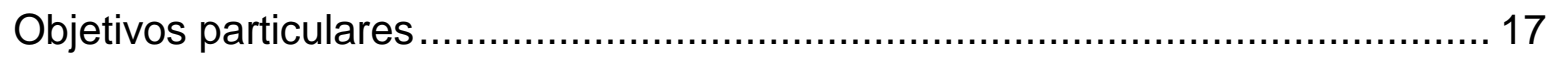

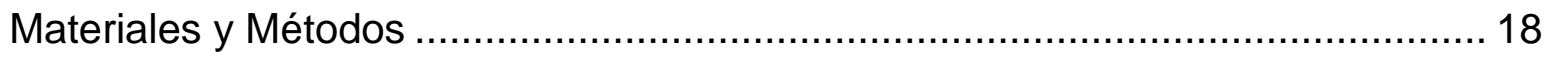

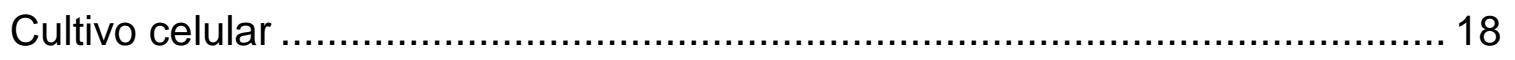

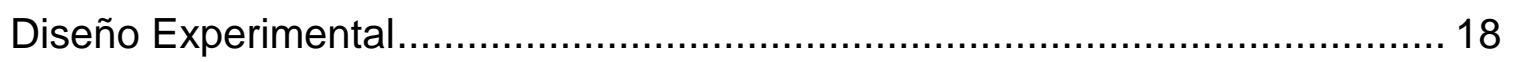

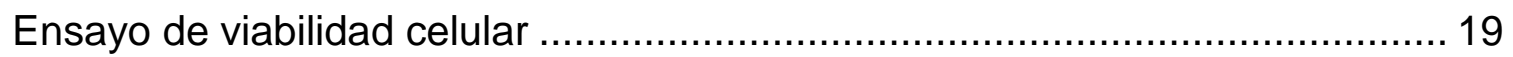


Extracción de proteínas totales.

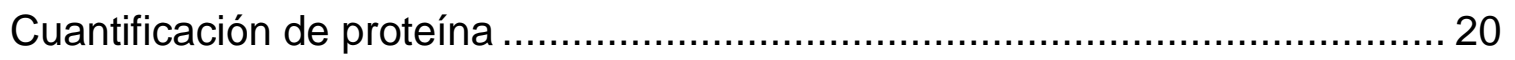

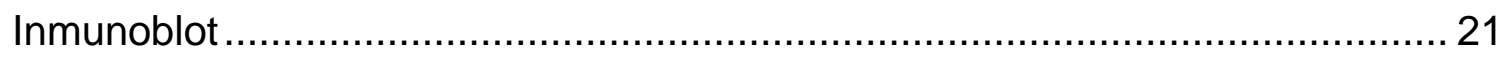

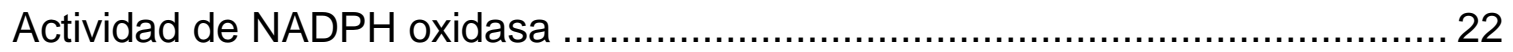

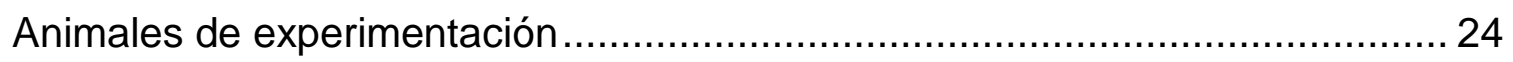

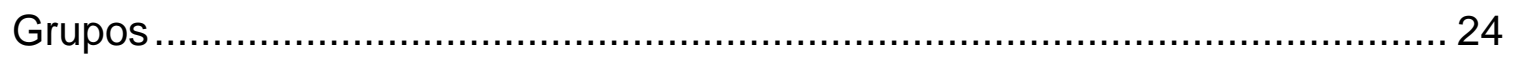

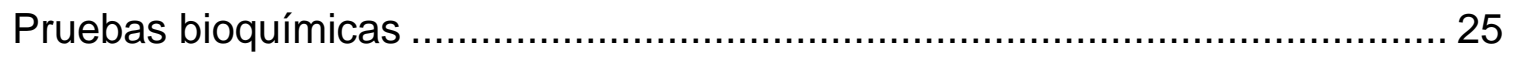

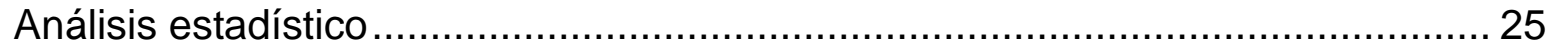

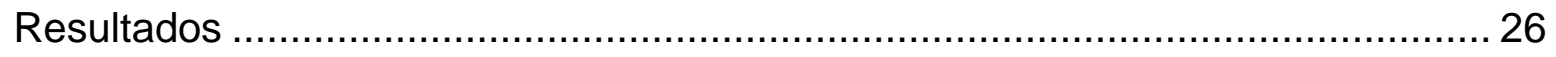

El etanol y el acetaldehído disminuyen la viabilidad celular ............................ 28

El tratamiento con HGF disminuye el efecto citotóxico del etanol y el

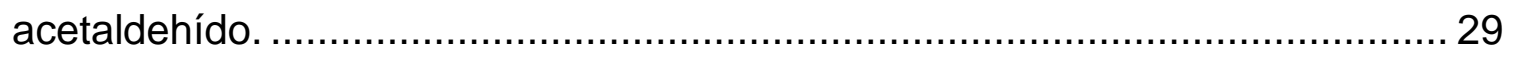

EI HGF desregula la actividad de la NADPH oxidasa.................................... 33

El HGF modula proteínas antioxidantes y de protección. .................................. 35

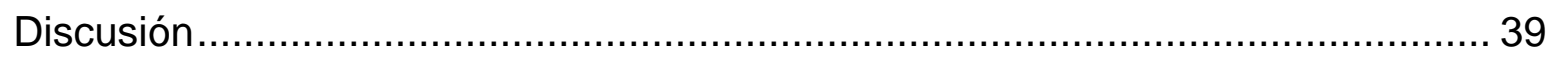

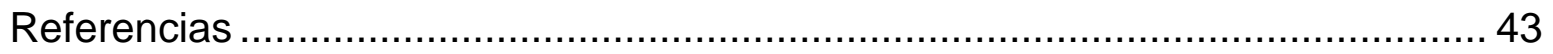




\section{Agradecimientos}

A la Universidad Autónoma Metropolitana Iztapalapa por abrirme las puertas al conocimiento.

Dr. Luis Enrique Gómez Quiroz le agradezco por enseñarme la pasión por el conocimiento, por guiarme, formarme como científica y persona, por toda la paciencia que me tuvo, por ser mi papá en la ciencia y por todo su apoyo incondicional, es un excelente ejemplo que seguiré en mi vida.

Dra. Ma. Concepción Gutiérrez Ruiz gracias por todo su apoyo, por ser un ejemplo como científica y persona.

Dr. Jens Uru Marquardt thank you so much for the great opportunity that you gave me in your laboratory at the Johannes Gutenberg University in Mainz Germany, I will try to follow you as good model of scientist and person.

A Conacyt por otorgarme la beca durante la maestría y de movilidad para mi estancia en Alemania.

A la Dra. Marcia hiriart Urdanivia, por sus comentarios a mi trabajo. Ha sido un honor tenerla en mi comité. A los doctores Mario Peláez, Francisco Alarcón, Julio Almanza por sus comentarios al trabajo y por aceptar ser mi jurado.

A la Dra. Leticia Bucio por invitarme al laboratorio de fisiología celular, y las doctoras Verónica Souza y Roxana Miranda por su apoyo. 


\section{Abreviaturas}

Ac: acetaldehído

ADH: alcohol deshidrogenasa

ADN: ácido desoxirribonucleico

Bax: por sus siglas en inglés BCL2-Associated $X$ Protein, proteina $X$ asociada a BCL2

c-Met: por sus siglas en inglés cellular mesenchymal transition, transición mesenquimal celular.

COX: ciclooxigenasa

CYP2E1: citocromo P4502E1

DM: diabetes mellitus

EGF: por sus siglas en inglés epidermal growth factor, factor de crecimiento epidermal

ERK 1/2: por sus siglas en inglés extracellular signal-regulated kinases, cinasas reguladas por señales extracelulares

EtOH: etanol

FGF: por sus siglas en inglés fibroblast growth factor, factor de crecimiento de fibroblastos

G6PD: glucosa 6 fosfato deshidrogenasa

GSH: glutatión

GSSG: glutatión oxidado

GSTM: glutatón transferasa de mamíferos 
$\mathrm{H}_{2} \mathrm{O}_{2}$ : peróxido de hidrogeno

HGF: por sus siglas en inglés Hepatocyte grow factor, factor de crecimiento de hepatocitos

MAPK: por sus siglas en ingles mitogen-activated protein kinase, proteínas cinasa activadas por mitógenos

NADPH oxidasa: nicotinamida adenina dinucleótido fosfato oxidasa

$\mathrm{O}_{2}^{*}:$ radical anión superóxido

$\cdot \mathrm{OH}$ : radical hidroxilo

PA: pancreatitis aguda

PC: pancreatitis crónica

PDGF: por sus siglas en inglés platelet-derived growth factor, factor de

crecimiento derivado de plaquetas

PI3K: cinasa 3 del fosfoinositol

ROS: por sus siglas en ingles reactive oxidative species, especies reactivas de oxígeno

SOD1: superóxido dismutasa 1

SOD2: superóxido dismutasa 2 


\section{Resumen}

El daño al páncreas es cada vez más frecuente en México, siendo el consumo de alcohol y la colelitiasis las causas más frecuentes; sin embargo, se sabe también de tener efecto directo el tabaquismo, la obesidad, entre otras causas. La pancreatitis es la principal manifestación de la afectación del órgano, pudiéndose presentar tanto aguda como crónica. Esta última puede conducir al agravamiento presentándose como procesos fibrogénicos o carcinogénicos. El HGF representa una alternativa para el control del daño y su reparación. En el presente trabajo nos centramos en dar un primer paso en caracterizar el efecto del HGF en el daño inducido por el etanol y su metabolito el acetaldehído, en una línea celular de páncreas como las células RINm5F. Los resultados muestran que el HGF es capaz de mejorar la sobrevivencia afectada por ambos tóxicos, incrementando proteínas antioxidantes, así mismo indujo un efecto desregulador en la NADPH oxidasa, una de las principales entidades prooxidantes y que eventualmente se activan bajo esquemas de daño. Una primera exploración en el posible mecanismo molecular de dicho efecto protector mostró la activación de la ruta de sobrevivencia de las MAPK's, particularmente la mediada por ERK1/2. Lo anterior correlacionó con un incremento en enzimas antioxidantes como producto de la estimulación con el HGF. Los resultados muestran que el HGF ejerce un efecto protector elevando enzimas antioxidantes y abrogando sistemas prooxidantes, efecto mediado por la ruta de señalización ERK1/2. El HGF puede representar un posible blanco terapéutico en el tratamiento de algunas patologías asociadas al páncreas. 


\section{Abstract}

Pancreatic diseases have been increased in Mexico and worldwide because changes in behaviors. The main risk factors for the development of pancreatitis are alcohol consumption and cholelithiasis, in addition to smoking and obesity that have been related to severe pancreatitis. The disease can proceed to stages more complicated such as fibrosis and cancer.

The present work was focused to figure out the effect of HGF in the control of the damage induced by the alcohol and its metabolite acetaldehyde in a pancreatic cell line, the RINm5F. Data presented here show that HGF is capable to induce a survival response in cells treated with both toxics increasing antioxidants enzymes and abrogating the activity of the NADPH oxidase, the main ROS induced system, which eventually activates mechanisms of damage. An approach to address the signal transduction initiated by HGF showed that MAPK pathway, particularly ERK $1 / 2$ is the main mechanism of protection. This correlated with the increment of antioxidant enzymes and the abrogation of NADPH oxidase activity and expression. HGF can represent a possible therapeutic target for the control of some pancreatic diseases. 


\section{Introducción}

Los cambios culturales que se dan como inercia del avance tecnológico y social generan también cambios en los hábitos alimenticios, de comportamiento y recreativos que, en gran medida. Pueden condicionar a desordenes metabólicos y a varias enfermedades.

Es bien conocido que la obesidad representa un serio problema de salud pública no sólo en México (Black, Watanabe et al., 2013), si no a nivel mundial. Por otro lado se ha venido reportando el incremento en el consumo de alcohol, en mucho por la gran cantidad de anuncios en medios de bebidas alcohólicas asociadas a la adquisición de estatus social. Sin mencionar el consumo de drogas y la automedicación que también representan un problema grave.

Con base en lo anterior no es difícil pensar que los órganos internos están recibiendo constantemente agresiones que pueden conducir a su mal funcionamiento o a la enfermedad.

Además del hígado, el páncreas es un órgano que recibe en gran medida el daño justamente por estos excesos, entre ellos el del consumo de alcohol (Lin, Chang et al., 2014). 


\section{El páncreas, breve monografía}

El páncreas tiene dos funciones centrales, las cuales se pensó por mucho tiempo eran independientes: en primer lugar, actúa como glándula endocrina al secretar insulina y glucagón al torrente circulatorio para mantener la homeostasis de la glucosa, funciones llevadas al cabo por las células beta y las alfa; en segundo lugar, es un órgano digestivo accesorio (glándula exocrina) que secreta un líquido rico en enzimas digestivas al tracto gastrointestinal (Pocock y Richards, 2005), el páncreas exocrino está formado por células acinares y células ductales que producen enzimas digestivas y bicarbonato de sodio respectivamente.

La secreción de la porción exocrina es modulada por señales neurales y hormonales. Algunos productos secretados por las células de los islotes, como insulina, interactúan directamente con las células acinares y regulan su función, se ha reportado que la diabetes reduce la función exocrina (Murakami, Fujita et al., 1992), esto sugiere una importante interacción entre los componentes endocrino y exocrino del páncreas. En vista de esto, una activación o inactivación inapropiada de las vías que median estos mecanismos de regulación tan finos poseen un impacto importante en la salud y en la enfermedad (Leung, 2010).

\section{Principales agentes de daño al páncreas}

Algunas de las principales causas que dañan al páncreas son, como se ha mencionado, el consumo de alcohol, la obstrucción de vías biliares por litiasis, y el tabaquismo, conduciendo a las afecciones en el páncreas exocrino tales como pancreatitis crónica $(\mathrm{PC})$, pancreatitis aguda $(\mathrm{PA})$ o adenocarcinoma pancreático, 
que pueden inducir disfunción endocrina manifestada como diabetes mellitus (DM). Ésta incluye a un grupo de enfermedades metabólicas que se caracterizan por hiperglucemia que resulta de defectos en la secreción o acción de la insulina, o la combinación de ambos (Diaz-Rubio, Torre-Delgadillo et al., 2002).

En el caso del etanol, se sabe que el páncreas es un órgano que, comparado con el hígado, posee la capacidad de metabolizar relativamente pequeñas cantidades de etanol por las células acinares, que expresan al citocromo P4502E1 (CYP2E1) ante una ingesta crónica de alcohol, la alcohol deshidrogenasa (ADH), la catalasa y la ácido graso etil éster sintasa que biotransforman al etanol (Bhopale, Falzon et al., 2014).

Por otro lado, las células ductales y las células beta del páncreas sólo poseen enzimas como la ADH y catalasa que metabolizan el etanol a acetaldehído (Seo, Gowda et al., 2013). Una característica particular de las células beta es que poseen una alta sensibilidad al estrés oxidante ya que tienen pocas enzimas antioxidantes como la superóxido dismutasa, catalasa y glutatión peroxidasa (Lenzen, 2008).

\section{El etanol y su metabolito el acetaldehído}

El etanol es un producto derivado de la fermentación de azúcares. La naturaleza anfifílica de los alcoholes les confiere ciertas propiedades particulares, de tal manera que pueden reaccionar con otras moléculas polares, por su naturaleza hidrofóbica pueden reaccionar con regiones hidrofóbicas de los lípidos y proteínas alterando así sus funciones. El efecto del etanol sobre las células, es debido a una 
interacción inespecífica del alcohol con la membrana que se traduce como un aumento en la fluidez de la misma y esta característica es muy importante para el funcionamiento normal de numerosas proteínas, de manera que un incremento en la fluidez altera las interacciones normales entre lípidos y proteínas (Chin y Goldstein, 1977).

De manera especial puede afectar la membrana mitocondrial la cual posee cantidades mínimas de colesterol. Chin y Goldstein (1977) reportaron que las membranas más resistentes al efecto tóxico del etanol son aquellas que contienen de 10 a $15 \%$ más colesterol que las membranas de animales controles, aspecto discutible por la toxicidad que el colesterol confiere, al mismo tiempo, a la misma mitocondria, sin embargo el dato aporta información de uno de los principales blancos del etanol.

Por otro lado al biotransformarse el etanol se obtiene como primer metabolito el acetaldehído que es altamente tóxico, mutagénico y carcinogénico ya que forma aductos en el ADN, inhibe su reparación, la metilación y daña el sistema de defensa antioxidante por lo cual puede, consecuentemente, resultar en el desarrollo de tumores (Seitz y Stickel, 2009).

Pero tal vez el principal efecto directo del acetaldehído es la formación de aductos, los cuales suelen alterar la estructura química donde se forman, induciendo mutaciones, o alteraciones en la funcionalidad de enzimas claves para la célula, conduciendo a procesos anormales que eventualmente permiten el inicio de enfermedades en el humano (Seitz y Stickel, 2009). 
Datos de nuestro grupo han mostrado que el acetaldehído es capaz de dañar a la mitocondria (Farfan Labonne, Gutierrez et al., 2009) generando estrés oxidante, y recientemente reportamos que en parte el mecanismo reside en el daño causado en la superóxido dismutasa 2 (SOD2) la cual es dañada severamente, pero con una rápida recuperación transcripcional, esto observado en células hepáticas de origen tumoral (Clavijo-Cornejo, Enriquez-Cortina et al., 2013), sin embargo este desorden, aún temporal, va acompañado de cambios en los niveles de especies reactivas de oxígeno (ROS), las cuales dirigen varios procesos tanto fisiológicos como patológicos.

\section{El estado redox celular y el estrés oxidante}

Las ROS, si bien es conocido que pueden dirigir funciones fisiológicas fundamentales para la células, cuando se producen en exceso son capaces de inducir disfunción celular e incluso la muerte por apoptosis o necrosis.

El buen manejo de las ROS por parte de la célula representa la mejor forma de adaptación ante los retos prooxidantes que reciben diariamente el cuerpo. La producción de anión superóxido por complejos como la mitocondria, la NADPH oxidasa, la xantina oxidasa, por mencionar algunos, es controlada por enzimas como la SOD1 ó 2, el cual lo transforman en peróxido de hidrógeno, y posteriormente la catalasa o la glutatión (GSH) peroxidasa, hace lo propio dejando dicha ROS en una molécula de agua. Si este sistema antioxidante fallara, permitiría la formación de un radical libre altamente reactivo como es el radical hidroxilo. 
Entre los sistemas prooxidantes más destacados se encuentra la nicotinamida adenina dinucleótido fosfato (NADPH) oxidasa capaz de producir ROS con el único objetivo de señalizar y activar rutas de señalización.

La NADPH oxidasa es un complejo multienzimático unido a membrana que cataliza la reducción de oxígeno al anión superóxido, utilizando NADPH como donador de electrones. Se descubrió en células fagocíticas como fuente de ROS para la eliminación de bacterias, pero también se encuentra en muchos tipos celulares (Bedard y Krause, 2007), como en las células hepáticas y pancreáticas (Dabrowski, Konturek et al., 1999; Fujimori, Oono et al., 2011; Clavijo-Cornejo, Enriquez-Cortina et al., 2013). La función de la NADPH oxidasa en células no fagocíticas no está completamente descrita, pero existe evidencia de su importancia en los eventos de la transducción de señales. Se ha reportado que la sobre expresión y sobre activación de la NADPH oxidasa induce estrés oxidante en el páncreas (Koulajian, Desai et al., 2013), en el hígado (Kaposi-Novak, Lee et al., 2006), y en el sistema cardiovascular (Fernandes, Wosniak et al., 2007), entre otros tejidos.

Además, la activación sostenida de la NADPH oxidasa correlaciona con patologías como la pancreatitis aguda (Yu, Lim et al., 2005), en la diabetes (Weaver y TaylorFishwick, 2013) y en cáncer (Edderkaoui, Nitsche et al., 2011).

La familia de las NADPH oxidasas consiste de diferentes proteínas catalíticas homólogas unidas a la membrana (NOX1-5, Duox1 y 2) y algunas proteínas reguladoras ( $\mathrm{p} 67, \mathrm{p} 47, \mathrm{p} 40$, Noxo1, Rac) estos últimos en condiciones normales se encuentran en el citoplasma, y se translocan a la membrana después de los 
estímulos apropiados para ensamblar al complejo activo de la NADPH oxidasa. La excepción es p22, una subunidad ubicuamente expresada que requiere de NOX14 para su activación y estabilización, p22 reside en la membrana y se cree que ayuda al plegamiento de la NOX o participa en el transporte de electrones (Bedard y Krause, 2007).

Recientemente nuestro grupo publicó que en hepatocitos el HGF es capaz de ejercer una regulación dual, incrementando o disminuyendo su activación, con el objeto de activar al factor de trasncripcion Nrf2 e inducir una respuesta de protección (Clavijo-Cornejo, Enriquez-Cortina et al., 2013).

Es bien conocido que el estrés oxidante juega un papel central en la patofisiología de la pancreatitis, tanto crónica como aguda y que puede perpetuar los síntomas clínicos e histológicos como el dolor, la fibrosis y la necrosis (Bhardwaj y Yadav, 2013). La sobre producción de ROS se debe al aumento de radicales libres producto del metabolismo de xenobióticos por las enzimas de fase I pertenecientes a la familia de los citocromos P450, estos sistemas suelen ser sobre expresados por tóxicos como el etanol, el humo del tabaco y tóxicos dietéticos, lo que reduce la capacidad de destoxificación de las enzimas de fase II al disminuir notablemente el contenido de GSH (Bhardwaj y Yadav, 2013).

Los niveles elevados de glucosa también inducen estrés oxidante en el páncreas, induciendo daño en prácticamente todos los tipos celulares del órgano, particularmente permite la activación de las células estelares que conducen a la fibrosis. El tratamiento con antioxidantes disminuyó notablemente tal efecto (Ryu, Lee et al., 2013) 
Con base a lo anterior, es indispensable que se mantenga siempre un estado redox celular balanceado para un correcto funcionamiento celular y del órgano. La figura 1 muestra de manera general el mecanismo que conduce a la homeostasis de las ROS.
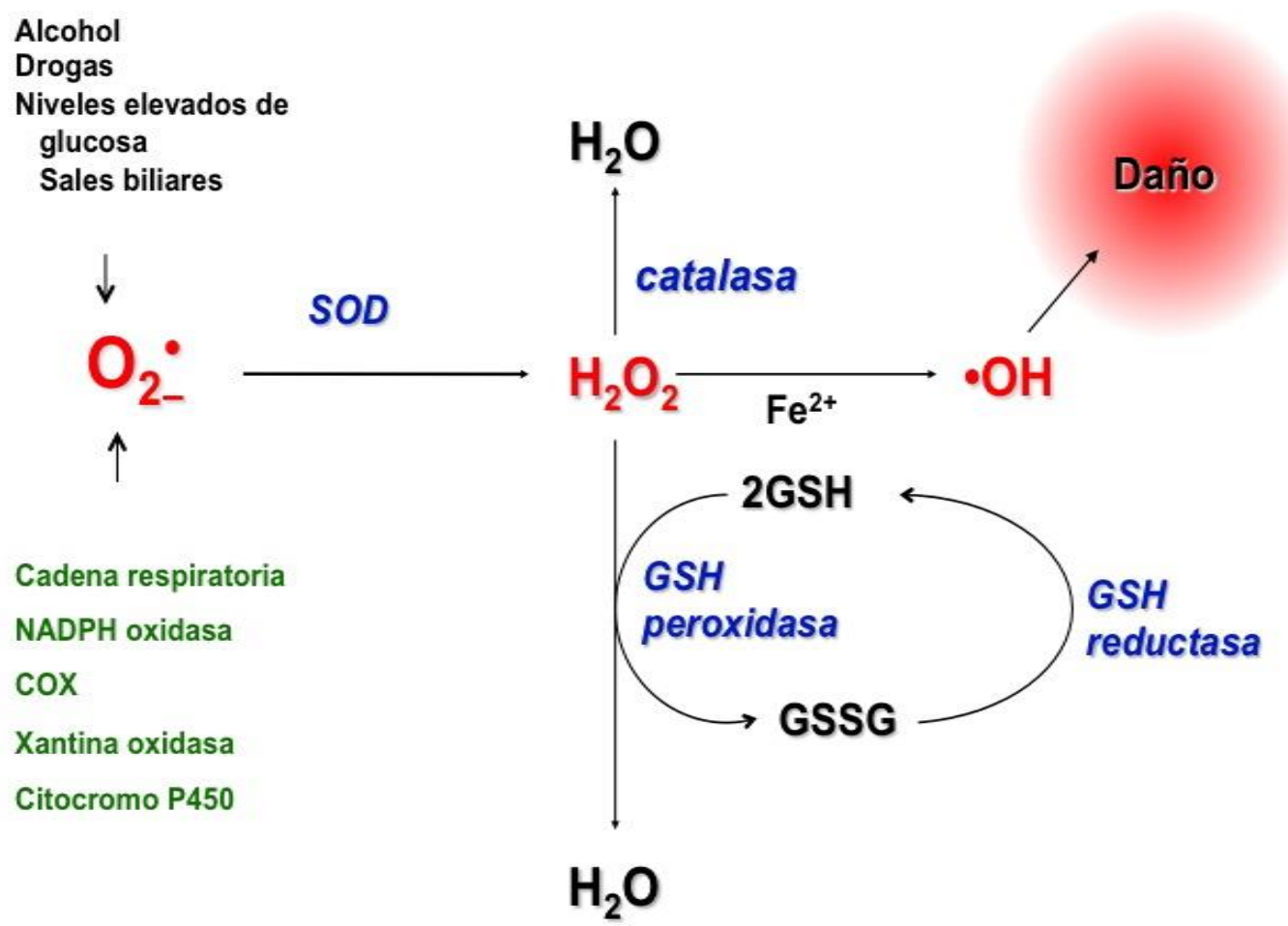

Figura 1. Homeostasis de las especies reactivas de oxígeno. $\mathrm{O}_{2^{\circ}}$, radical anión superóxido; $\mathrm{H}_{2} \mathrm{O}_{2}$, peróxido de hidrógeno; $\bullet \mathrm{OH}$, radical hidroxilo; $\mathrm{SOD}$, superóxido dismutasa; GSH, glutatión. 
Así pues, sea el daño por formación de aductos de acetaldehído, por alteración en el estado redox celular y el estrés oxidante causado tanto por el etanol como por el acetaldehído, la célula debe mantenerse en constante adaptación para evitar el mal funcionamiento del órgano.

\section{Factores de crecimiento y la protección celular}

Los factores de crecimiento son proteínas que inician una respuesta de reparación, sobrevivencia y proliferación en tejidos, particularmente epiteliales, tanto en estados fisiológicos como patológicos, por ejemplo, inducidos por el desbalance redox iniciado por el etanol o sus metabolitos.

Se han caracterizado varios factores de crecimiento a lo largo del tiempo, como el factor de crecimiento epidermal (EGF), el derivado de plaquetas (PDGF), el de fibroblastos (FGF) y el de hepatocitos (HGF), este último tiene efectos en prácticamente todos los tejidos epiteliales, no solo en el hepático.

La ruta de señalización del HGF participa en el control de múltiples funciones bilógicas como las que se han mencionado, adicionalmente ejerce efecto contra la apoptosis y, nuestro grupo de investigación ha venido caracterizando ampliamente, el control del estado redox celular y el estrés oxidante (GomezQuiroz, Factor et al., 2008; Nakamura y Mizuno, 2010).

La unión del HGF a su receptor c-Met, receptor con actividad de tirosina cinasa, lleva a la autofosforilación de tirosinas específicas localizadas dentro del bucle de activación del dominio catalítico e inicia la actividad catalítica intrínseca del receptor (Bertotti y Comoglio, 2003). El HGF también induce la fosforilación de 
otras tirosinas donde se reclutan mediadores como la cinasa 3 del fosfoinositol (PI3K), la enzima de intercambio de nucleótidos de guanina mSOS, que a su vez permite la activación de la ruta de las RAS/MAPK, particularmente de ERK1/2, las cuales están estrechamente relacionadas con fenómenos de proliferación, sobrevivencia y reparación en tejidos epiteliales (Bertotti y Comoglio, 2003). (Aparicio I.M., Garcia-Marin L.J. et al., 2003).

El conocimiento del mecanismo por el cual estas rutas de señalización conducen a la protección, proliferación o sobrevivencia, representan, sin lugar a dudas, un punto central en la búsqueda de nuevas estrategias terapéuticas contra problemas como la pancreatitis o la diabetes mellitus.

\section{Antecedentes}

En el 2004 con la creación del ratón MetKO (Huh, Factor et al., 2004), entre otros muchos aspectos, mostró que la eliminación de Met induce estrés oxidante por la sobreactivación de la NADPH oxidasa (Gomez-Quiroz, Factor et al., 2008) lo que condicionaba a la sensibilización a otros agresores. Posteriormente identificamos que HGF/Met regulan dualmente a la oxidasa en condiciones normales, teniendo

un efecto bifásico y tendiendo a controlar el estado redox y la sobrevivencia y protección (Clavijo-Cornejo, Enriquez-Cortina et al., 2013), además hemos encontrado, como un posible mecanismo de regulación, que la subunidad de la NADPH oxidasa p22 interactúa directamente con el receptor Met (Datos sin publicar Clavijo-Cornejo, Investigación doctoral, 2014). En busca de aspectos aún 
más fisiológicos de esta regulación del estado redox por HGF y Met el grupo se enfocó a estudiar el impacto de ello en cáncer (Kaposi-Novak, Lee et al., 2006; Takami, Kaposi-Novak et al., 2007), fibrosis (Marquardt, Seo et al., 2012) y daño por fármacos (DILI), particularmente los antifímicos (Enriquez-Cortina, AlmonteBecerril et al., 2013), en estos estudios observamos que la ausencia de Met condiciona a un desarrollo acelerado de cáncer, el cual es revertido en presencia de N-acetil cisteína, un precursor de glutatión (GSH) y antioxidante, que es dirigido por la señalización del HGF. Por otro lado, esta particularidad de que HGF/Met controla el estado redox celular fue estudiada por microarreglos y relacionado a un mal pronóstico y fenotipo agresivo en pacientes con hepatocarcinoma (KaposiNovak, Lee et al., 2006) .

Mientras que en el caso de la fibrosis inducida por el tetracloruro de carbono, se observó un agravamiento de la enfermedad en ratones MetKO, con un claro compromiso en la desregulación del estado redox celular (Marquardt, Seo et al., 2012). En el caso del modelo de DILI, vimos que el daño hepatotóxico inducido por la rifampicina y la isoniazida en ratones, se ve significativamente disminuido, casi a niveles basales, cuando los ratones son sometidos al tratamiento con HGF exógeno, o se ve exacerbado cuando es tratado con anti-HGF. Adicionalmente estudiamos dicho efecto en un modelo in vitro de enfermedad hepática alcohólica, donde vimos el mismo resultado por un mecanismo mediado, al menos en parte, por NF-kB (Valdes-Arzate, Luna et al., 2009).

El presente trabajo está enfocado en dar los primeros acercamientos al efecto del HGF a nivel pancreático, 


\section{Pregunta de investigación}

¿Ejercerá el HGF una respuesta de protección contra retos prooxidantes en células de origen pancreático como las RINm5F?

\section{Hipótesis}

El HGF inducirá una respuesta de sobrevivencia, mediada por NADPH oxidasa y Nrf2, en células de origen pancreático sometidas a retos prooxidantes que permitirá la sobrevivencia ante estos estímulos citotóxicos.

\section{Objetivo general}

Determinar el efecto protector del HGF en células de origen pancreático (RINm5F) sometidas a retos prooxidantes

\section{Objetivos particulares}

1. Determinar el efecto protector del HGF en la viabilidad de células RINm5F sometidas a tratamientos con etanol y acetaldehído.

2. Evaluar la actividad de la NADPH oxidasa en las células RINm5F y su modulación por el HGF

3. Determinar el mecanismo molecular ejercido por el HGF que media la respuesta de sobrevivencia en las células RINm5F 


\section{Materiales y Métodos}

\section{Cultivo celular}

Las células RINm5F, línea celular derivada de un insulinoma de rata, se obtuvieron de la American Type Culture Collection (ATCC, Rockville, MD, EUA), en el pasaje 37, se cultivaron en medio RPMI 1640 el cual se suplementó con 10\% de suero fetal bovino (SFB, Hy-Clone, Logan, UT, EUA), $100 \mathrm{U} / \mathrm{mL}$ de penicilina y $100 \mu \mathrm{g} / \mathrm{mL}$ de estreptomicina. En adelante a este medio se le llamará medio completo. Las células se sembraron en botellas de cultivo de plástico estériles (Corning, Acton, MA, EUA). El medio de cultivo se cambió cada tercer día. Las células se resembraron a una dilución 1:3 una vez por semana, levantándose con tripsina-EDTA al $0.25 \%$. El cultivo se mantuvo con una atmósfera de $5 \%$ de $\mathrm{CO}_{2}$ y $90 \%$ de humedad, a una temperatura de $37^{\circ} \mathrm{C}$.

\section{Diseño Experimental}

Se sembraron las células en cajas Petri de $6 \mathrm{~cm}$ (Corning) con medio completo. Se dejó estabilizar el cultivo por 24 h. Posteriormente se cambió el medio por uno libre de SFB durante $12 \mathrm{~h}$. Todos los tratamientos con el factor de crecimiento de hepatocitos (HGF, PeproTech, México) se realizaron a una concentración de 50 $\mathrm{ng} / \mathrm{ml}$ a tiempos de $0,6,12$ y $24 \mathrm{~h}$ para extracción de proteína total y a 0, 15 y 30 min., 1, 3, 6, 12 y $24 \mathrm{~h}$ para la actividad de la NADPH oxidasa.

Los tratamientos con etanol (EtOH 100 mM, J.T Baker), acetaldehído (Ac $200 \mu \mathrm{M}$, Sigma Aldrich) y peróxido $\left(\mathrm{H}_{2} \mathrm{O}_{2} 200 \mu \mathrm{M}\right)$ se realizaron a 12,24 y $48 \mathrm{~h}$. 
Los pretratamientos con el HGF se realizaron por $12 \mathrm{~h}$ previo a la exposición con los tóxicos, las cajas se sellaron con parafilm para evitar la evaporación del EtOH y del Ac.

La densidad celular utilizada fue de $51 \times 10^{3}$ células por centímetro cuadrado.

\section{Ensayo de viabilidad celular}

Las células se sembraron a una densidad de $51 \times 10^{3}$ células $/ \mathrm{cm}^{2}$ en placas estériles de 96 pozos (Nunc), una por agente tóxico, se dejaron estabilizar por $6 \mathrm{~h}$

y se cambió el medio completo a medio sin SFB por 12 h, se aplicó o no el pretratamiento con el HGF por $12 \mathrm{~h}$ y posteriormente se adicionó el EtOH o el Ac por 12 y 24 h, se utilizó $\mathrm{H}_{2} \mathrm{O}_{2}$ como control positivo por $12 \mathrm{~h}$.

Al finalizar los tratamientos se cambió el medio a medio sin SFB adicionando en cada pozo $100 \mu \mathrm{LL}$ y $10 \mu \mathrm{L}$ del reactivo CCK-8 (Cell Counting Kit 8, Dojindo Inc.) se incubó $1 \mathrm{~h}$ en condiciones estándar de cultivo celular. El kit consiste en la reducción de una sal soluble de tetrazolio WST-8 mediante deshidrogenasas en la célula que da como producto un color naranja el cual se detectó a $450 \mathrm{~nm}$ en un lector multimodal de placas DTX 880 (Beckman Coulter, Inc).

\section{Extracción de proteínas totales}

Al terminó de los tratamientos las células se lavaron con PBS, se rasparon los platos de cultivo con un gendarme, se concentraron las células en un botón en microtubos y se realizó la extracción de proteínas mediante el buffer de lisis MPER (Thermo Scientific) suplementado con $10 \mathrm{mM}$ ditiotreitol (DTT), $1 \mathrm{mM}$ fluoruro 
de fenilmetilsulfonilo (PMSF), por cada $10 \mathrm{~mL}$ se adicionó una pastilla de inhibidor de proteasas (Complete, Roche Applied Science, Indianapolis, USA) y una pastilla de inhibidor de fosfatasas (PhosphoStop, Roche Applied Science, Indianapolis, USA). Los lisados se mantuvieron en microtubos en hielo y se dieron tres ciclos en vortex de 10 segundos, se centrifugaron a $13000 \mathrm{rpm}, 15 \mathrm{~min}$ a $4^{\circ} \mathrm{C}$. Se hicieron alícuotas y se congelaron a $-80^{\circ} \mathrm{C}$ hasta ser utilizadas (Gomez-Quiroz, Factor et al., 2008; Clavijo-Cornejo, Enriquez-Cortina et al., 2013; Enriquez-Cortina, Almonte-Becerril et al., 2013).

\section{Cuantificación de proteína}

La determinación de la concentración de proteína se realizó mediante el método del ácido bicinconínico o BCA (Pierce Biotechnology, USA), siguiendo las instrucciones del fabricante. Se tomó una alícuota del $5 \mu \mathrm{L}$ de las muestras y se le agregó $200 \mu \mathrm{L}$ de reactivo $\mathrm{BCA}$ diluido $1: 50$ y se incubó por 30 min a $25^{\circ} \mathrm{C}$. Se

realizó una curva patrón con albúmina sérica bovina de 0.1-0.5 mg/mL. Posteriormente se leyó la absorbancia en el detector multimodal (DTX880) y se determinó la concentración de la proteína utilizando la curva estándar de albúmina sérica de bovino (Gomez-Quiroz, Factor et al., 2008; Clavijo-Cornejo, EnriquezCortina et al., 2013; Enriquez-Cortina, Almonte-Becerril et al., 2013). 


\section{Inmunoblot}

Se tomaron $100 \mu \mathrm{g}$ de la proteína total y se le agregó amortiguador de muestra $2 \mathrm{X}$ (Laemmli sample buffer, Bio Rad). Las muestras se dejaron 5 min a 95ㄷ y se separaron en geles de poliacrilamida al $10 \%$ en presencia de SDS al $0.1 \%$, usando 120 volts por 90 min. La proteína se transfirió a una membrana de difloruro de polivinilideno (PVDF, G.E. Health care amersham Pharmacia Biotechnology, USA), durante 30 min a 25 volts, 1 Ampere, en el equipo trans-blot turbo (Bio Rad) usando un amortiguador de transferencia preparado con Tris-Base $25 \mathrm{mM} \mathrm{pH} \mathrm{8.3,}$ glicina $192 \mathrm{mM}$ y metanol al 20\%. Posteriormente la membrana fue bloqueada con una solución de leche descremada al $5 \%$ en TBS-Tween 20 durante 30 min. Al finalizar, se retiró el exceso de leche con TBS-Tween 20, se incubó con el anticuerpo primario en cuestión y que se especifican en el cuadro 1 durante toda la noche a $4^{\circ} \mathrm{C}$ en agitación lenta o durante $1 \mathrm{~h}$ a temperatura ambiente. Se lavó dos veces con TBS-Tween 20 durante $10 \mathrm{~min}$. Posteriormente se incubó el anticuerpo secundario acoplado a la peroxidasa de rábano a una dilución 1:8000 (GE health care Inc) por $1 \mathrm{~h}$ a temperatura ambiente. La membrana se lavó dos veces con TBS-Tween 20 durante $10 \mathrm{~min}$ y un lavado con TBS por $5 \mathrm{~min}$. Se reveló con $1 \mathrm{~mL}$ de sustrato luminiscente (SuperSignal West Pico Substrate, Pierce), las bandas se cuantificaron por densitometría en un equipo imaging system gel logic 1500 (Kodak) (Gomez-Quiroz, Factor et al., 2008; Clavijo-Cornejo, Enriquez-Cortina et al., 2013). 


\begin{tabular}{|l|l|l|}
\hline \multicolumn{1}{|c|}{ Anticuerpo } & Dilución: Secundario & \multicolumn{1}{|c|}{ Marca } \\
\hline GSTM 23KDa & $1: 200$ Anti- conejo & Santa Cruz Biotechnology. Inc \\
\hline SOD 1 22 KDa & $1: 3000$ Anti-conejo & Santa Cruz Biotechnology. Inc \\
\hline Catalasa 60 KDa & $1: 3000$ Anti-ratón & Sigma Aldrich \\
\hline NQO1 32 KDa & $1: 200$ Anti-conejo & Santa Cruz Biotechnology. Inc \\
\hline K-ERK 1/2 42, 44 & $1: 5000$ Anti-conejo & Cell Signaling Technology \\
\hline ERK 1/2 42, 44 KDa & $1: 5000$ Anti-conejo & Cell Signaling Technology \\
\hline p-AKT T308 60 kDa & $1: 5000$ Anti-conejo & Cell Signaling Technology \\
\hline AKT 60 kDa & $1: 5000$ Anti-conejo & Cell Signaling Technology \\
\hline p-STAT 3 S727 & $1: 5000$ Anti-conejo & Cell Signaling Technology \\
\hline STAT 3 & $1: 5000$ Anti-conejo & Cell Signaling Technology \\
\hline
\end{tabular}

Cuadro 1. Anticuerpos primarios utilizados, con peso en $K D a$, anticuerpo secundario y marca.

\section{Actividad de NADPH oxidasa}

Terminados los tratamientos con el HGF se lavaron las células con PBS siempre mantenidas en hielo, se retiró el buffer y se agregó buffer de lisis compuesto por tris- $\mathrm{HCl} 50 \mathrm{mM}$ pH7.4, EGTA $0.1 \mathrm{mM}$, EDTA $0.1 \mathrm{mM}$, PMSF $1 \mathrm{mM}$, aprotinina y leupeptina $10 \mu \mathrm{M}$, se rasparon las células con un gendarme, se recuperaron en microtubos y se sonicaron 3 veces por 10 segundos en hielo, seguido de centrifugación a $14,000 \mathrm{rpm}$ durante $15 \mathrm{~min}$ a $4^{\circ} \mathrm{C}$ posteriormente se recuperó el 
sobrenadante en microtubos, tratando de no tomar el botón que son principalmente células no lisadas y mitocondrias, se centrifugó a 33,000 rpm por 1h a $4^{\circ} \mathrm{C}$, en una centrífuga Beckman modelo TL-100 se decantó el sobrenadante y la fracciones membranales se recuperaron en $100 \mu \mathrm{L}$ del buffer de lisis en tubos nuevos, se sonicaron por 3 seg y se realizó la cuantificación de proteína mediante el reactivo de Bradford (Bio Rad) utilizando las especificaciones técnicas del comerciante, se realizó una curva utilizando albumina sérica de bovino. Se utilizaron $20 \mu \mathrm{g}$ de proteína para determinar la producción de superóxido.

En placa oscura de 90 pozos se agregaron $20 \mu \mathrm{g}$ de proteína completando a 60 $\mu \mathrm{L}$ con PBS, se adicionó o no a pozos clururo de difenileneiodonio (DPI, Sigma Aldrich, inhibidor de la NADPH oxidasa y otras flavoproteínas) a $10 \mu \mathrm{M}$ por 30 min, como control a otros pozos se les adicionó superóxido dismutasa $250 \mathrm{U} / \mathrm{mg}$ (SOD, Sigma Aldrich), se adicionó una mezcla formada por buffer de fosfatos 50

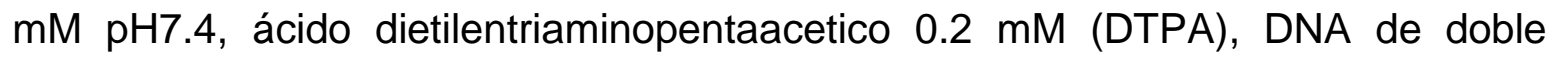
cadena $1.25 \mu \mathrm{g} / \mathrm{mL}$ por pozo, NADPH6 $\mu \mathrm{M}$, dihidroetidio $2.4 \mu \mathrm{M}$ (DHE, Invitrogene), se incubo a $37^{\circ} \mathrm{C}$ y se leyó la flourescencia durante una hora con intervalos de 5 minutos, con un filtro de excitación de 485 nm y de emisión 535 nm en un equipo Multimode Detector (DTX880, Beckman Coulter) (Clavijo-Cornejo, Enriquez-Cortina et al., 2013). 


\section{Animales de experimentación}

El estudio se llevó al cabo en ratones macho de 8 a 10 semanas de edad de la cepa CD1. Todos los procedimientos con los animales se realizaron con estricto apego a la NOM-062-ZOO-1999 y a los lineamientos de uso de animales del NIH (Guidelines for the use of animals in intramural research NIH).

\section{Grupos}

Cada grupo se formó con 3 ratones repartidos de manera aleatoria. Los grupos fueron:

Grupo A. Ratones control con inyecciones ip e iv de solución salina isotónica.

Grupo B. Ratones con inyecciones ip de ceruleína (Cn). 8 inyecciones de $50 \mu \mathrm{g} / \mathrm{kg}$ cada hora, con sacrificio a las $24 \mathrm{~h}$ de haber iniciado la primera dosis de $\mathrm{Cn}$.

Grupo C. Ratones con una dosis de HGF $20 \mu \mathrm{g} / \mathrm{kg}$ al inicio del tratamiento conjuntamente con la primera dosis, de ocho, de Cn. Los ratones se sacrificaron a las $24 \mathrm{~h}$ de haber iniciado el estudio.

Grupo D. Ratones tratados con una sola dosis de HGF y sacrificados a las $24 \mathrm{~h}$. 


\section{Pruebas bioquímicas}

El daño pancreático se determinó midiendo la actividad de amilasa pancreática por medio de métodos automatizados empleando un equipo Reflotron (Roche Inc) usando tiras reactivas Reflovet (Roche Inc).

\section{Análisis estadístico}

Cada experimento se realizó por triplicado en al menos tres experimentos independientes. El análisis estadístico de los resultados obtenidos se realizó mediante análisis de varianza (ANOVA), seguido por la prueba post hoc no paramétrica de Bonferroni. Se empleó para el análisis el programa GraphPad Prism 6. El nivel mínimo de significancia fue de $p \leq 0.05$. 


\section{Resultados}

Con la finalidad de evaluar el daño inducido por el EtOH y su metabolito el Ac, se realizaron curvas de viabilidad donde se trataron a las células RINm5F hasta por $48 \mathrm{~h}$, utilizando concentraciones fisiológicas reportadas en humanos tras una ingesta aguda de alcohol (Gomez-Quiroz, Paris et al., 2005), se utilizó peróxido de hidrogeno como control positivo a diferentes concentraciones. En la figura 2 se puede observar que la viabilidad disminuye significativamente con respecto al tiempo cuando las células se trataron tanto con $\mathrm{EtOH}$ (figura 2A) como con el Ac (figura 2B) y $\mathrm{H}_{2} \mathrm{O}_{2}$ (figura 2C). De estos datos se decidió tomar los tiempos de 12 y $24 \mathrm{~h}$ y del $\mathrm{H}_{2} \mathrm{O}_{2}$ la concentración de $200 \mathrm{mM}$ para los experimentos posteriores de viabilidad. 
A)

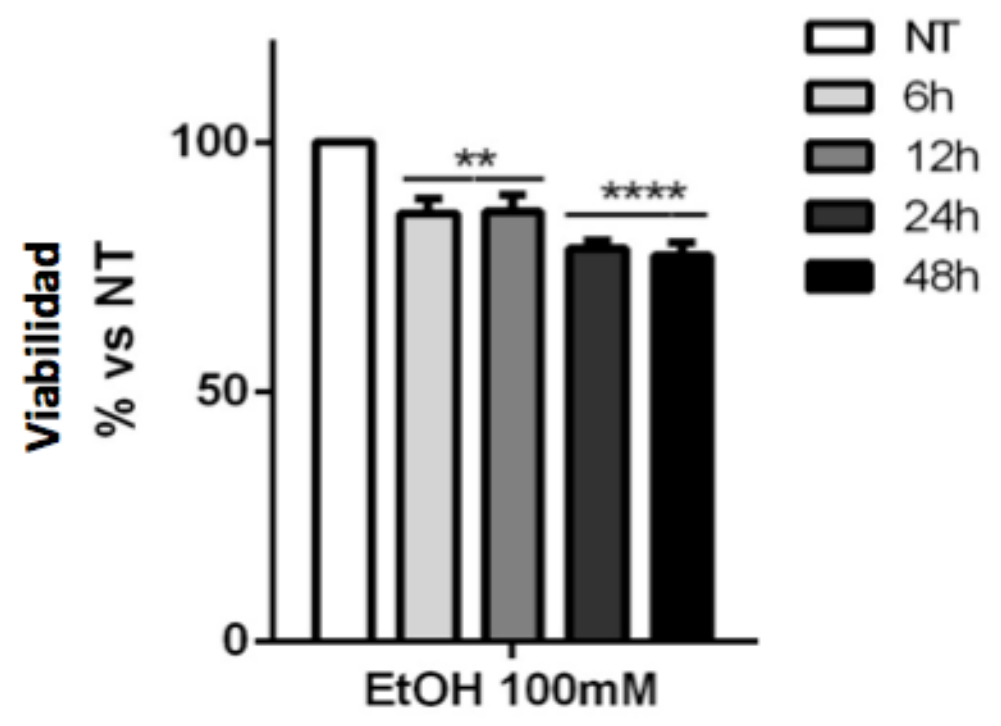

B)

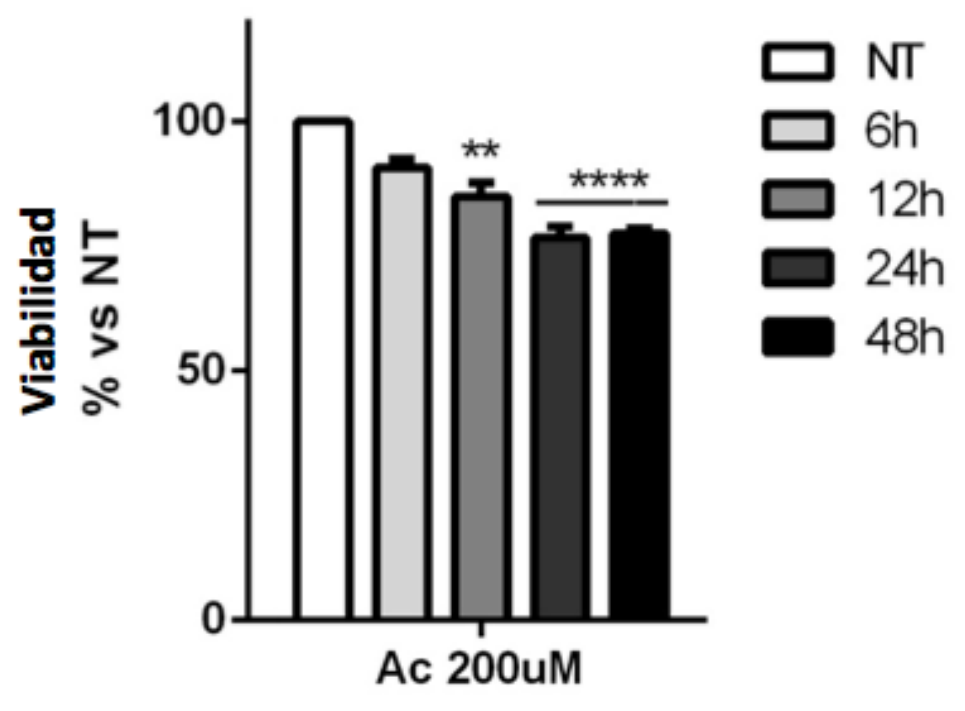




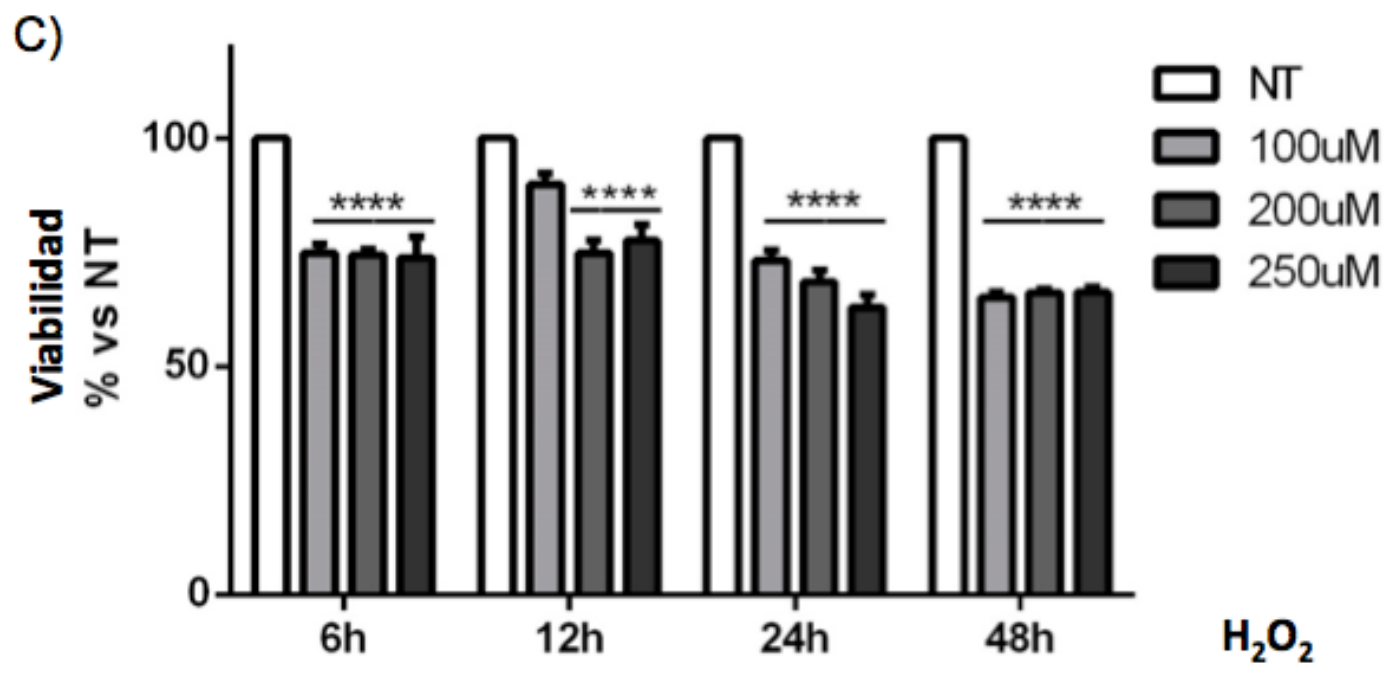

Figura 2. Viabilidad de células RINm5F tratadas con, A) etanol $100 \mathrm{mM}$, B) acetaldehído 200 M y C) peróxido de hidrógeno 100, 200 y $250 \mu$ M. En los tres casos por 6, 12, 24 y 48 horas. Los valores representan el promedio ( \pm E.E.) de al menos 3 experimentos independientes llevados al cabo por triplicado. Diferencia significativa con respecto al control $\left.{ }^{* *} p<0.05 ;{ }^{* * *} P<0.001\right)$.

\section{El etanol y el acetaldehído disminuyen la viabilidad celular}

Se evalúo el daño ejercido por los tóxicos en el cultivo celular mediante microscopia de luz. En la figura 3 se observa que el daño correlaciona con la viabilidad mostrada anteriormente, ya que a partir de las $12 \mathrm{~h}$ de exposición al EtOH se muestran cambios importantes que se incrementan a las $24 \mathrm{~h}$ y con el Ac se aprecian células dañadas desde las 6 h y es más notorio a las 24 y $48 \mathrm{~h}$ al igual que en el caso del $\mathrm{H}_{2} \mathrm{O}_{2}$ causando un mayor daño al cultivo. Se puede apreciar que el daño con dichos tóxicos es dependiente del tiempo, se observan células 
con condensación citoplasmática, en Zeiosis, también se observa la formación de vesículas citoplásmicas por estrés celular y cuerpos apoptóticos.

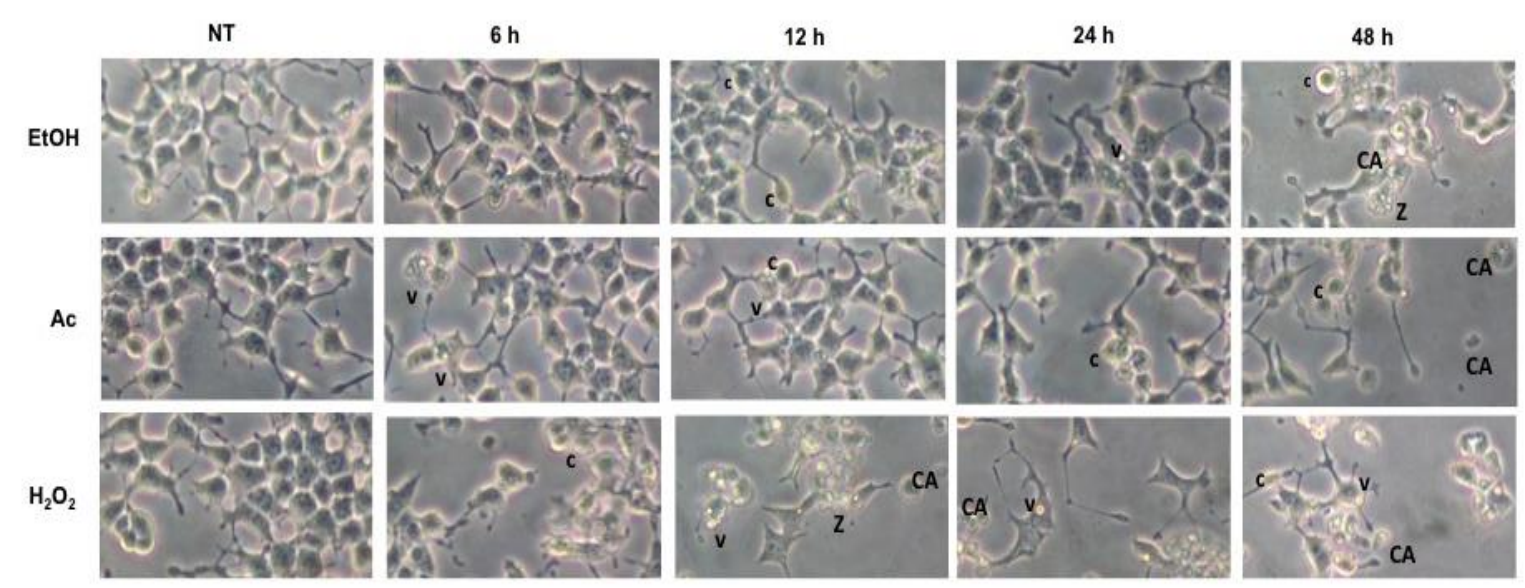

Figura 3. Aspecto morfológico del cultivo de células RINm5F tratadas con etanol (EtOH, $100 \mathrm{mM}$ ) o acetaldehído (200 uM) por diferentes tiempos. Aumento original 100X. Imágenes representativas de al menos 3 experimentos independientes. Condensación citoplasmática (C), Zeiosis (Z), vesículas citoplásmicas (V) y cuerpos apoptóticos (CA)

\section{El tratamiento con HGF disminuye el efecto citotóxico del etanol y el acetaldehído.}

Posteriormente se probó el efecto protector propuesto para el HGF, para lo cual se pretrató el cultivo con el factor por $12 \mathrm{~h}$ y después se expusieron a los tóxicos por 12 y $24 \mathrm{~h}$. Como se puede observar en la figura 4 el EtOH y su metabolito el Ac disminuyeron significativamente la viabilidad celular, pero en ambos casos 
aquellas células pretratadas con el HGF recuperan su viabilidad significativamente con respecto a las que no tuvieron pretratamiento con el HGF.

A)

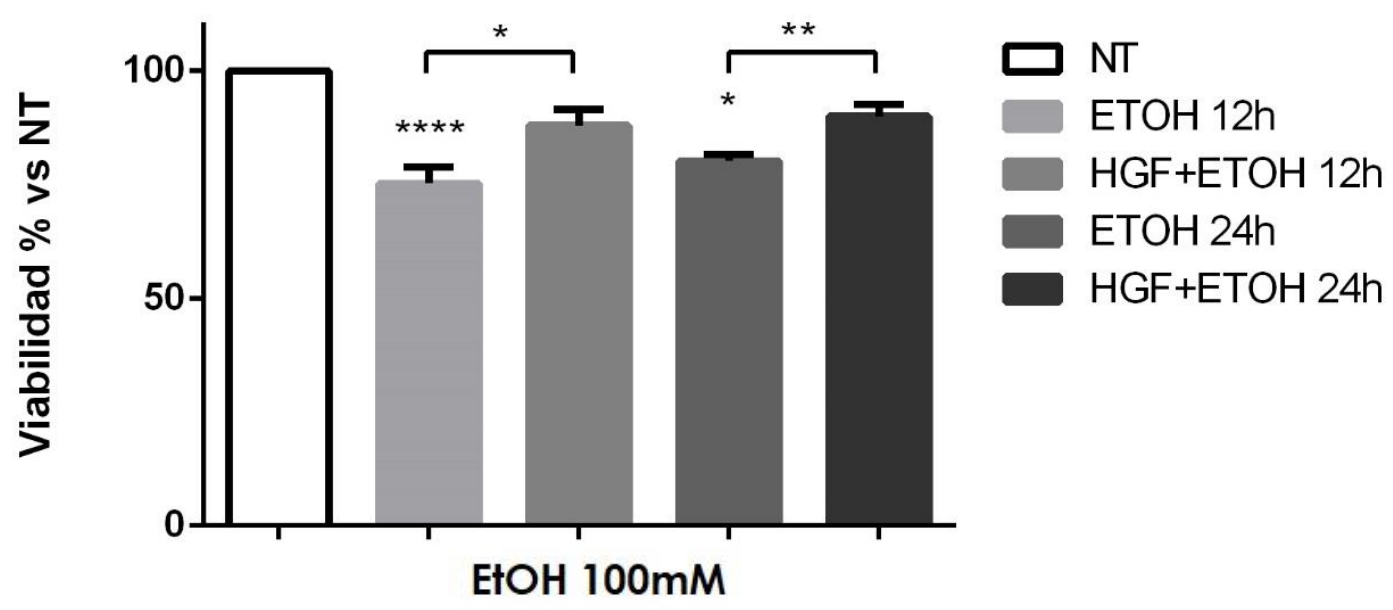

B)

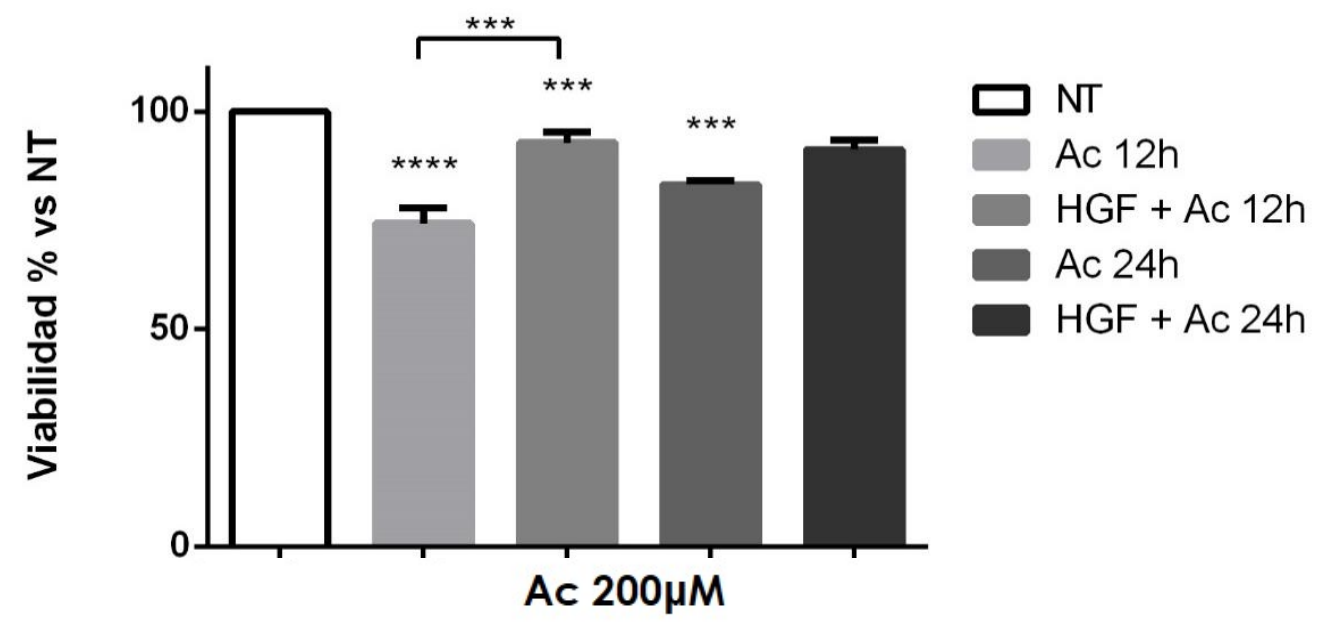


C)

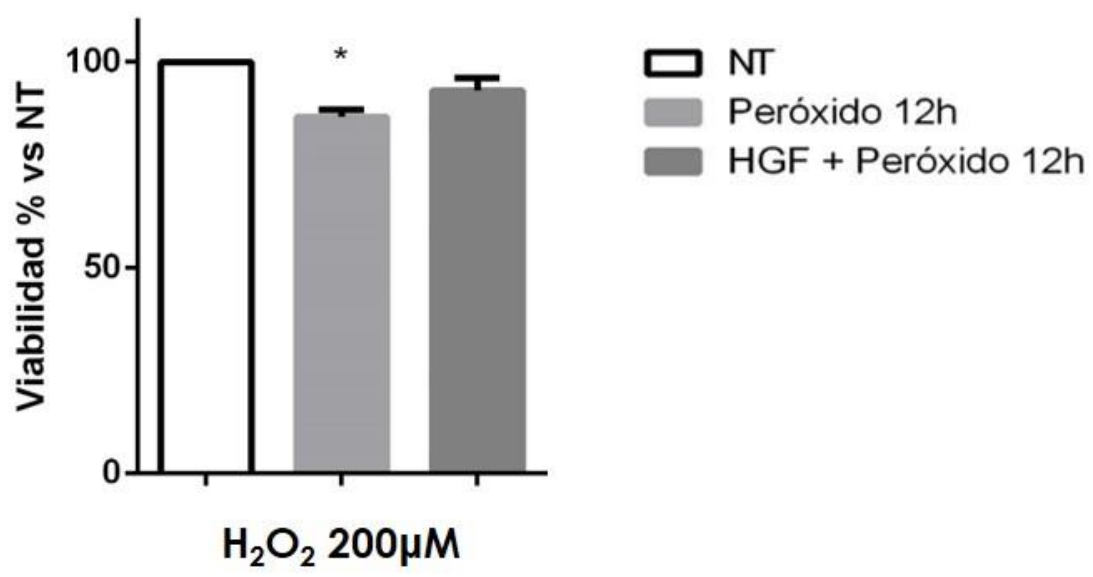

Figura 4. EI HGF induce una respuesta de sobrevivencia ante los tóxicos. Viabilidad de células RINm5F pretratadas o no con HGF $50 \mathrm{ng} / \mathrm{mL}$ y $12 \mathrm{~h}$ despúes con A) etanol 100 mM, (B) acetaldehído $200 \mu M$, o (C) peróxido de hidrógeno $200 \mu$ M, en los tres casos por 12 y 24 h. Los valores representan el promedio ( \pm E.E.) de al menos 3 experimentos independientes llevados al cabo por triplicado. * Diferencia significativa con respecto al control $(p<0.05),{ }^{* *}$ diferencia significativa $(p<0.001),{ }^{* * *}$ diferencia significativa $(p<$ $0.0001)$. 


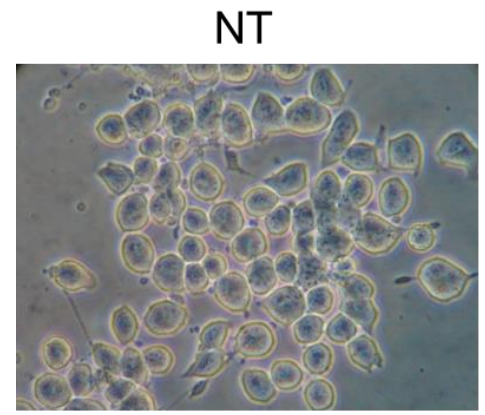

HGF

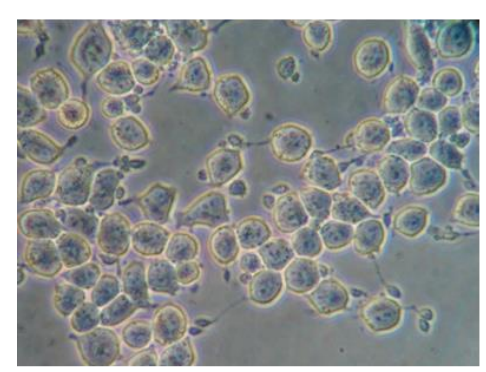

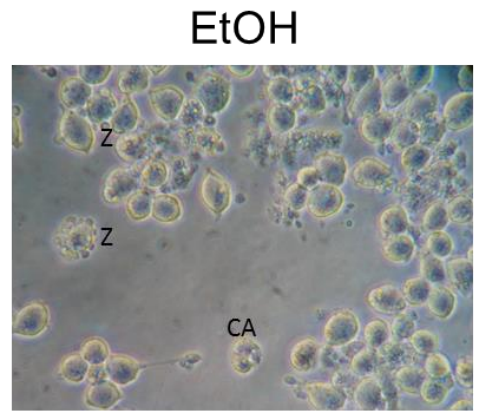

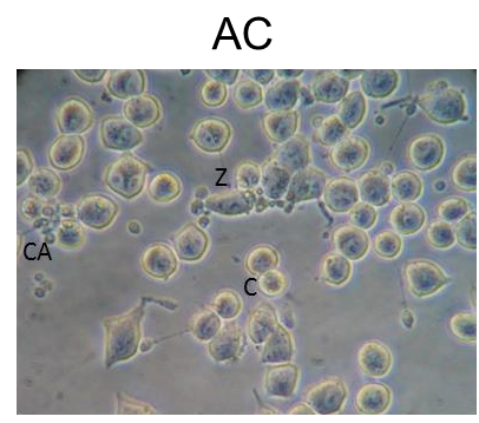

$\mathrm{H}_{2} \mathrm{O}_{2}$

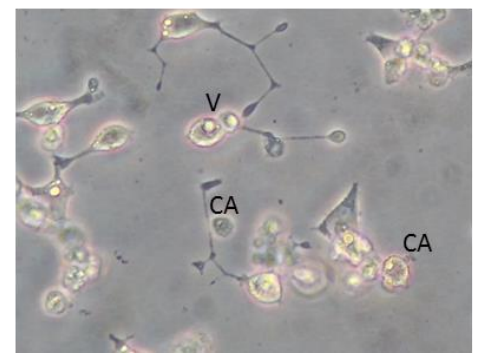

$\mathrm{HGF}+\mathrm{EtOH}$

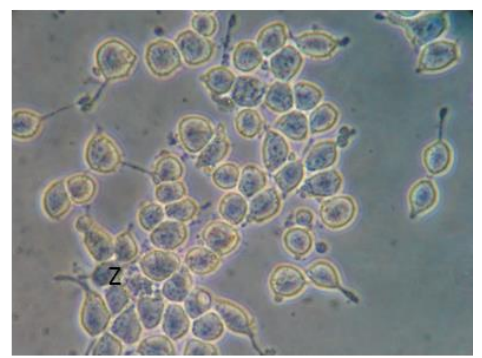

$\mathrm{HGF}+\mathrm{Ac}$

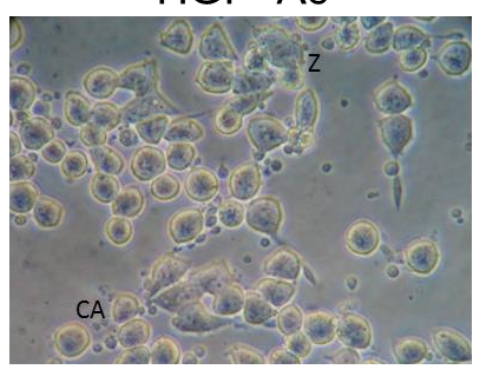

$\mathrm{HGF}+\mathrm{H}_{2} \mathrm{O}_{2}$

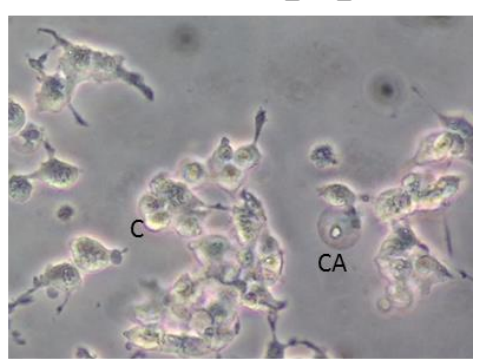

Figura 5. Microscopia de luz, células RINm5F tratadas o no con HGF por $12 h$,

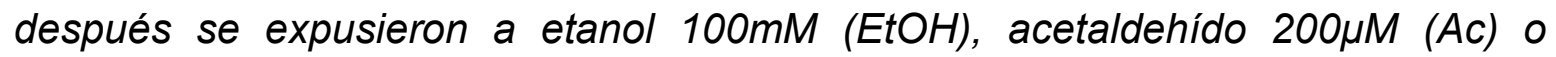
peróxido de hidrogeno 200 $\mu$ M (H2O2) por 24 h. Aumento 320X. Condensación citoplasmática (c), cuerpos apoptóticos (CA), vesículas citoplásmicas (V), zeiosis $(Z)$. 
Para confirmar el efecto protector del HGF ante los tóxicos se tomaron microscopias de luz para observar la morfología del cultivo. Como se aprecia en la figura 5 el HGF tiene un efecto protector cuando se pretrató al cultivo por $12 \mathrm{~h}$ y después se expusieron a los tóxicos: etanol, acetaldehído y peróxido de hidrógeno durante $24 \mathrm{~h}$. Se puede observar que el HGF disminuye el proceso de muerte celular.

\section{EI HGF desregula la actividad de la NADPH oxidasa}

Posteriormente se realizó la determinación de la producción del anión superóxido $\left(\mathrm{O}^{2}\right.$.- $)$ generado por la NADPH oxidasa en fracciones membranales, a tiempos

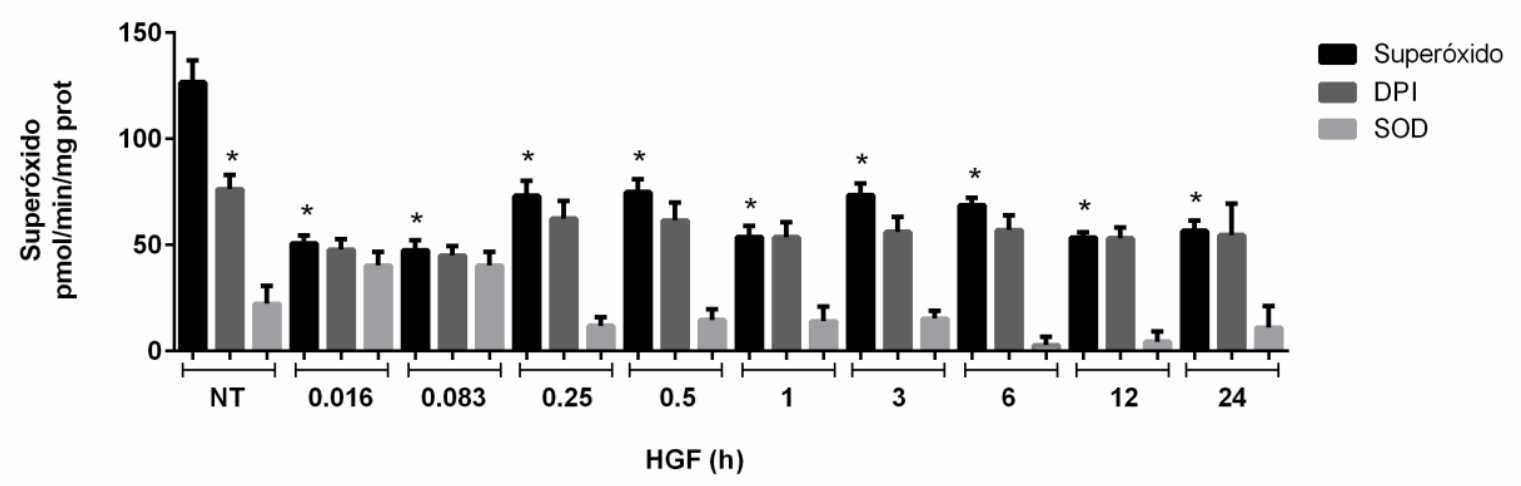

Figura 6. Actividad de la NADPH oxidasa por determinación de superóxido. Se trataron las células y se procedió al aislamiento de fracciones, se utilizó como control el tratamiento con SOD y DPI para inhibir a la NADPH oxidasa. Las columnas representan el promedio de al menos 5 experimentos independientes con al menos 5 repeticiones cada uno. ANOVA de una vía, post hoc Bonferroni, * diferencia significativa vs superóxido NT $p<0.001$. 
cortos y a tiempos largos de las células RINm5f tratadas con HGF, la figura 3 muestra que el HGF disminuye la producción de $\mathrm{O}^{2}$.- reprimiéndola desde el minuto de tratamiento y se mantiene hasta las $24 \mathrm{~h}$.

Con la finalidad de caracterizar aún más el efecto del HGF sobre la NADPH oxidasa se realizó la exploración por Western blot de NOX1, la cual se ha reportado ser una de las principales subunidades catalíticas en páncreas y particularmente de las células beta (Weaver y Taylor-Fishwick, 2013), y de p22 la cual es compartida por las NOX1 a la 5. La figura 7 muestra el efecto represor del HGF en ambas proteínas, es sorprendente la represión de p22 desde las 6 h de tratamiento.

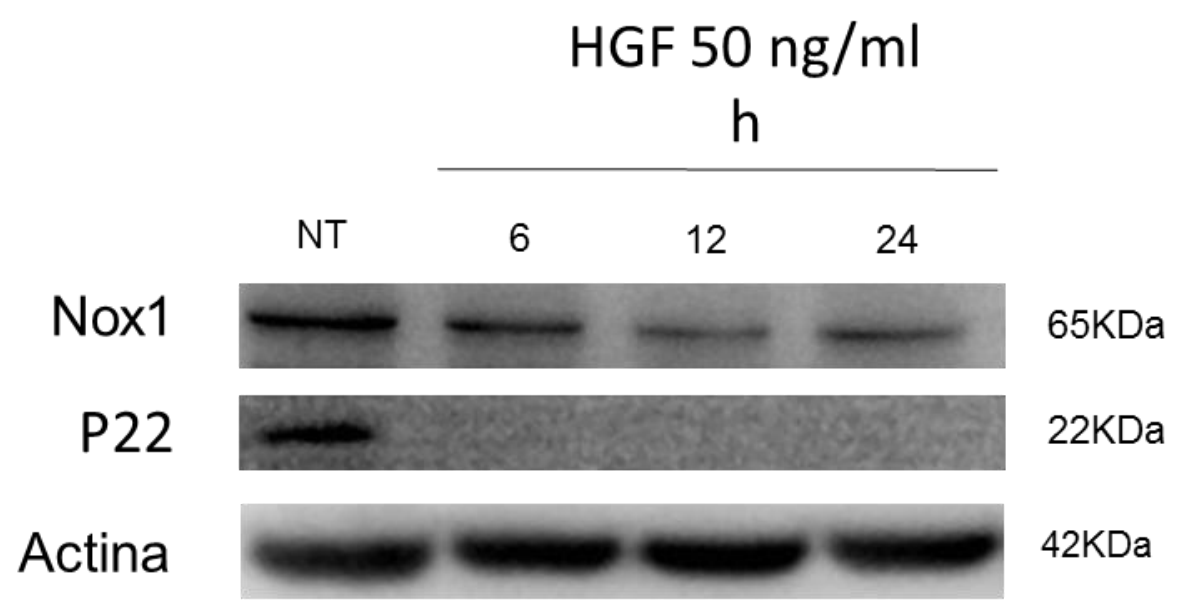

Figura 7. Efecto represor del HGF en NOX1 y p22. Las células fueron tratadas por 6,12 y 24 h con HGF. Se extrajo proteína total y se corrió una serie de Western blot como se especifíca en material y métodos. La imagen es representativa de al menos tres experimentos independientes. La actina se usó como control de carga 


\section{EI HGF modula proteínas antioxidantes y de protección.}

Con la finalidad de tener evidencia molecular de las posibles proteínas encargadas en la inducción del efecto protector se realizó una serie de Western blots de proteínas antioxidantes y de citoprotección. La figura 8 muestra que el HGF induce la expresión de la GSH transferasa (GSTM), enzima encargada del procesamiento de xenobióticos. De la misma forma se expresa la glucosa 6 fosfato deshidrogenasa (G6PD) encargada de la producción del NADPH el cual es requerido para el reciclamiento del GSH por la GSH reductasa. Interesantemente la SOD1, muestra una tendencia a disminuir con el tiempo de exposición con HGF, sugiriendo en gran medida la disminución en la producción de superóxido. La catalasa no mostró cambio alguno.

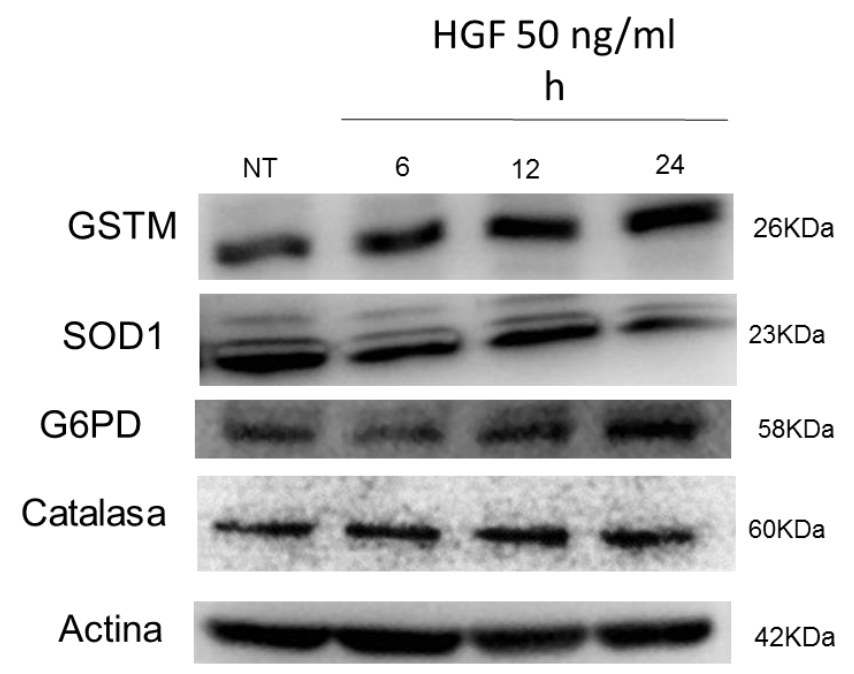

Figura 8. EI HGF modula la expresión de proteínas antioxidantes. Las células fueron tratadas por 6,12 y 24h con HGF. Se extrajo proteína total y se corrió una serie de Western blot como se específica en material y métodos. La imagen es representativa de al menos tres experimentos independientes. La actina se usó como control de carga 
Por otro lado, la figura 9 muestra el efecto del HGF en la expresión de Bax, principal proteína proapoptótica involucrada en pancreatitis (Xiping, Dijiong et al., 2009), la cual es disminuida a $24 \mathrm{~h}$ de tratamiento. Mientras que la principal efectora de la apoptosis, la proteína p38, de la ruta de las MAPK está completamente desactivada desde las $6 \mathrm{~h}$ hasta las $24 \mathrm{~h}$, lo cual deja claro el efecto antiapoptótico del HGF.

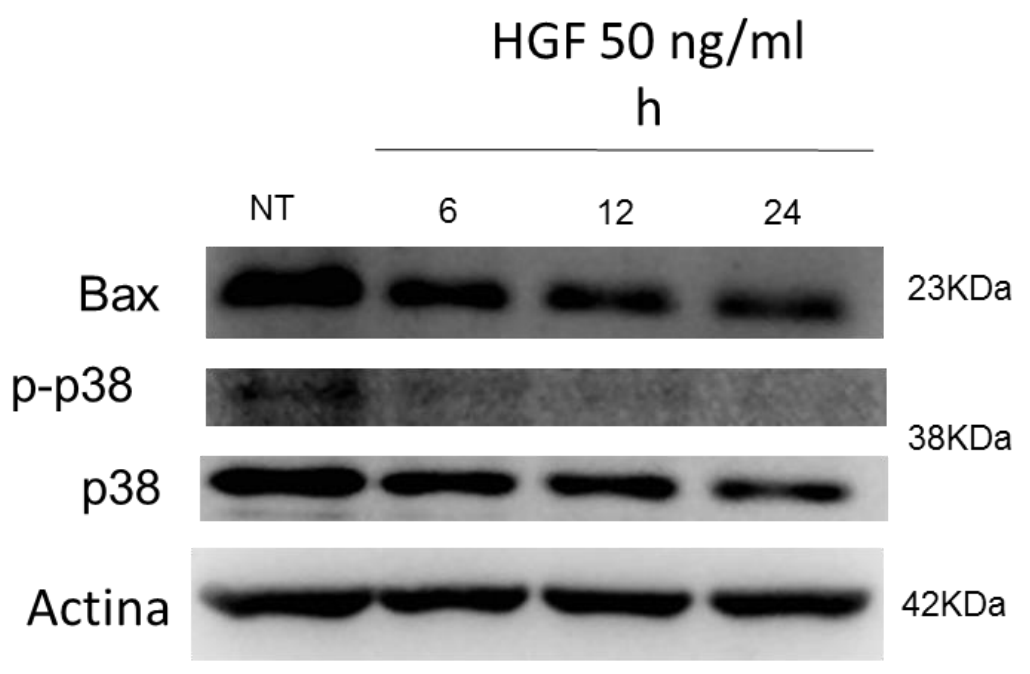

Figura 9. EI HGF disminuye la activación y expresión de proteínas que dirigen citotoxicidad Las células fueron tratadas por 6,12 y 24h con HGF. Se extrajo proteína total y se corrió una serie de Western blot como se específica en material y métodos para Bax, p-p38 y p38 total. La imagen es representativa de al menos tres experimentos independientes. La actina se usó como control de carga 
Finalmente, para conocer qué rutas de señalización activadas por el HGF podrían estar dirigiendo la respuesta de sobrevivencia se analizaron las rutas de ERK1/2, Akt y stat3, esta última no mostró cambio alguno, sin embargo Akt mostró una activación importante al igual que ERK1/2 la cual se relacionó con su cinasa activadora MEK1/2 que mostró un patrón muy similar a ERK1/2, confirmando de esta forma la activación de la ruta de sobrevivencia mediada por ERK1/2.

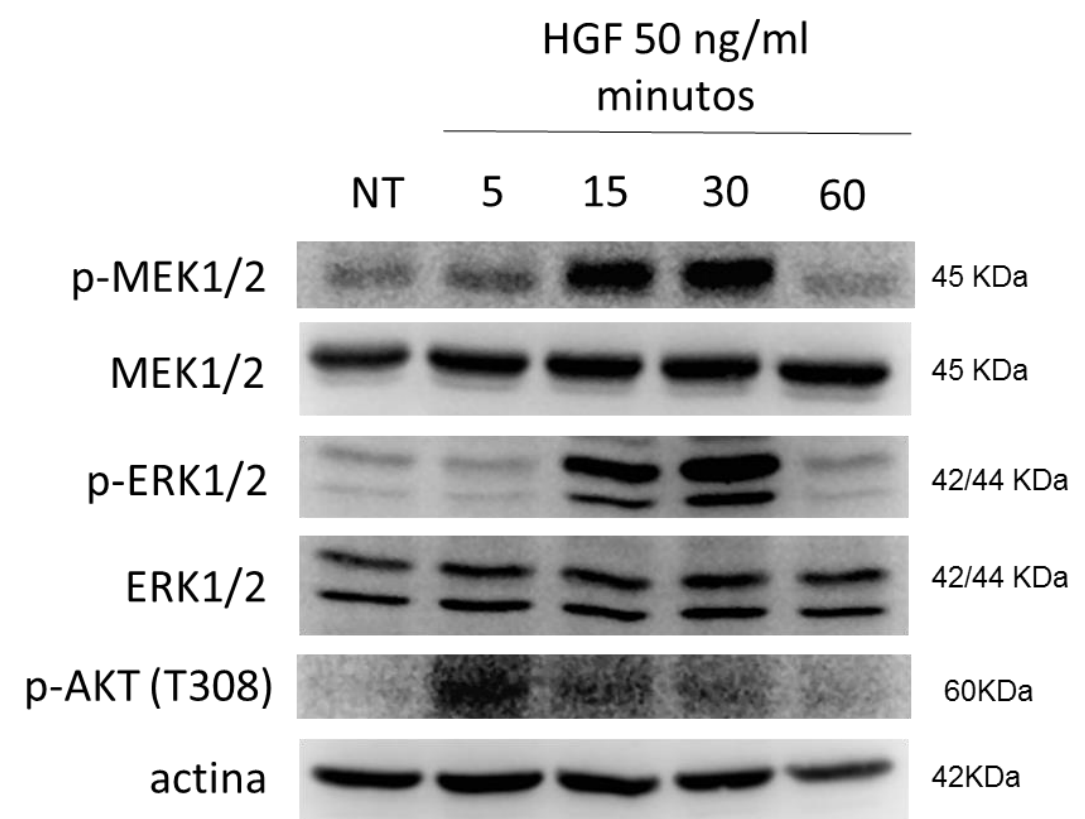

Figura 10. El HGF activa las rutas de sobrevivencia mediadas por Akt y ERK1/2. Las células fueron tratadas por 6,12 y 24h con HGF. Se extrajo proteína total y se corrió una serie de Western blot como se específica en material y métodos para MEK, ERK1/2 y Akt. La imagen es representativa de al menos tres experimentos independientes. La actina se usó como control de carga 
Con el objetivo de conocer si el efecto protector del HGF mostrado en los estudios in vitro pudiera tener una relevancia a nivel del páncreas en animales de experimentación, realizamos un estudio preliminar con ratones CD1 a los cuales se les administró HGF en la vena de la cola, dosis única de $20 \mu \mathrm{g} / \mathrm{kg}$, y posteriormente se les, administró celureína (Cn), 8 dosis cada hora, los ratones se sacrificaron a las $24 \mathrm{~h}$ después de la primera dosis de celureína y se obtuvo sangre para la determinación de amilasa pancreática

La figura 11 muestra los niveles de amilasa sérica en los ratones de experimentación, como se puede observar la celureína elevó la actividad de la enzima en sangre, mientras que el HGF disminuyó significativamente dicho incremento, demostrándose el efecto protector del HGF a nivel sistémico.

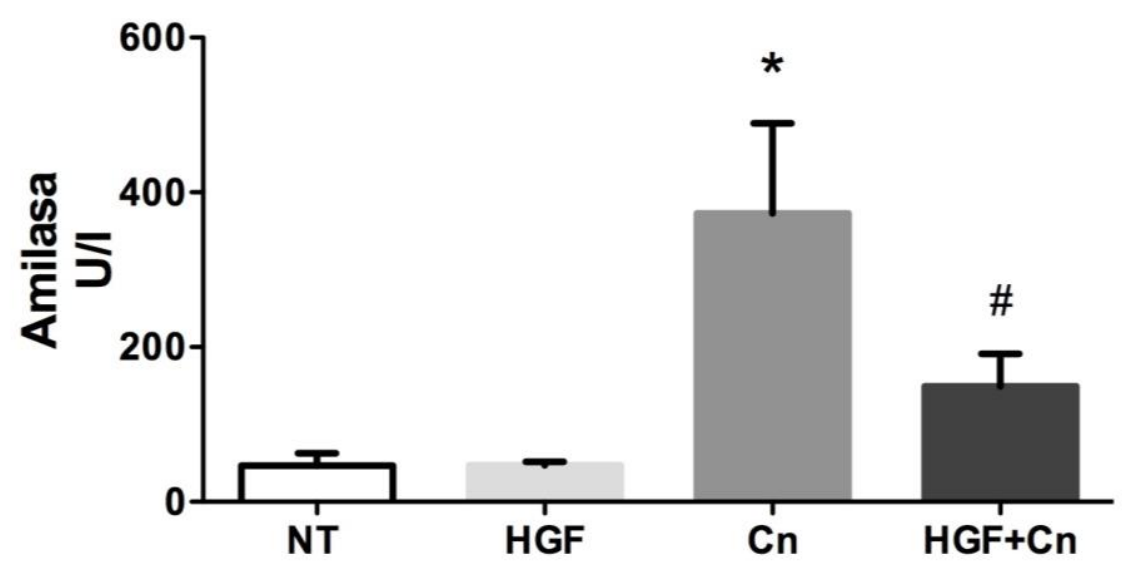

Figura 11. EI HGF induce una respuesta de protección en el páncreas en animales tratados con celureína. Ratones macho CD1 fueron divididos en los grupos que se especifican y se sometieron al tratamiento indicado en material y métodos. La actividad de la amilasa pancreática fue determinada. Cada barra representa el promedio de tres ratones \pm SEM. ${ }^{*} p<0.05$ vs NT, ${ }^{\#} p<0.05$ vs $C n$. 


\section{Discusión}

En la introducción a este trabajo se mencionaba lo preocupante que es ya el hecho de que varios factores de riesgo para el desarrollo de enfermedades de páncreas se estén elevando, particularmente el consumo de alcohol, la obesidad que eventualmente condiciona la aparición de colelitiasis (Park, Song et al., 2014). Es importante conocer de qué forma el sistema natural de protección del organismo lidia con los mediadores de daño que inician un proceso patológico.

¿Por qué usar este modelo de estudio? La experiencia que se tiene en el grupo de investigación referente al efecto del HGF como modulador del estado redox celular y control del estrés oxidante, muestra el papel relevante en el hígado. Hemos querido avanzar en la comprobación de la generalización de este efecto hacia otros órganos y, dado que es bien sabido la estrecha relación que tiene el hígado y el páncreas, nos centramos al estudio en este órgano, iniciando primeramente en un modelo in vitro empleando células de origen pancreático. Las células RINm5F (ATCC CRL-11605) provienen de un insulinoma de rata, por lo que derivaron de la transformación de una célula beta. Las células producen y secretan insulina lo que las hace, hasta cierto punto, un modelo adecuado para estudios de daño, ya que el efecto autocrino de la insulina producida le induce señales de protección. Por otro lado, elegimos el realizar casi en su totalidad el trabajo en esta línea celular con la intención de caracterizar un linaje celular el cual se relaciona en gran medida con la principal enfermedad que afecta al páncreas a nivel mundial, la diabetes. 
El estrés oxidante ha sido implicado en múltiples enfermedades, sin quedar aún claro el mecanismo de regulación de dicho proceso. Pareciera irónico pensar el hecho de que las ROS pueden, al mismo tiempo, ser entidades dañinas e iniciar señales de sobrevivencia y reparación.

El páncreas no escapa de lo mencionado arriba. En este reporte de la investigación nos hemos enfocado al estudio de cómo el HGF regula la homeostasis redox en las células RINm5F, induciendo una respuesta protectora ante estímulos canónicos como el etanol y su metabolito.

Con la finalidad de validar el daño celular realizamos una serie de experimentos de viabilidad usando el reactivo CCK8. En la figura 2 mostramos que ciertamente los tóxicos etanol y acetaldehído disminuyen significativamente la viabilidad celular. El peróxido de hidrógeno se empleó como control positivo de daño oxidante. En todos los casos se observa un daño dependiente del tiempo de exposición. Las concentraciones de etanol $(100 \mathrm{mM})$ y de acetaldehído $(200 \mu \mathrm{M})$ usadas en el estudio corresponden a los niveles fisiológicas alcanzados en el humano tras un consumo agudo de etanol (Gomez-Quiroz, Paris et al., 2005).

Lo anterior se ve claramente relacionado con el aspecto morfológico del cultivo celular, observándose un deterioro celular así como muerte en las células RINm5F (figura 3). Ha sido bien documentado el efecto tóxico del etanol y sus metabolito en el páncreas (Binker y Cosen-Binker, 2014), no solo en células de linaje beta, sino también en células acinares pertenecientes al páncreas exógeno (Bhopale, Falzon et al., 2014), describiéndose particularmente un daño mediado por estrés oxidante. En el presente trabajo confirmamos tales hallazgos. 
Datos de nuestro grupo han mostrado que el etanol induce una respuesta multivariada de daño, induciendo daño oxidante, lipoperoxidación, así como elevando la secreción de citocinas proinflamatorias como el TNF-alfa y la interleucina 8 efecto que se ve abrogado cuando los tóxicos se agregan en presencia de antioxidantes como $\mathrm{N}$-acetil cisteína (NAC) o tetrametil tiourea (Gomez-Quiroz, Bucio et al., 2003; Gomez-Quiroz, Paris et al., 2005)

El HGF, como protector contra el daño oxidante generado por el EtOH y el Ac, ha mostrado tener una efectividad elevada al ejercer una respuesta antioxidante elevando enzimas antioxidantes, como SOD y catalasa, así como en el sistema de GSH, efecto dirigido por la activación del factor de transcripción NFkB (ValdesArzate, Luna et al., 2009; Sancho y Fabregat, 2011), sin embargo en células RINm5F se muestra un efecto disminuido de SOD1 y no se encontraron cambios en catalasa, lo cual sugiere un efecto diferencial.

Lo anterior podría explicarse por el hecho de que se encontró mucho más elevado la ruta de MAPK mediada por ERK1/2, la cual tiene su principal factor de transcripción en AP1, más que en NFkB. La relevancia de esta diferencia tendría que ser estudiada mucho más afondo para obtener información concluyente o confirmatoria.

Otro aporte importante, y al mismo tiempo relevante, es también el efecto diferencial encontrado en términos de la NADPH oxidasa, ya que mientras en hepatocitos el HGF la regula positivamente a tiempo tempranos con la finalidad de producir ROS con fines de activación del factor Nrf2, lo cual ha sido reportado en el grupo por Clavijo-Cornejo y colaboradores (2013), en el presente trabajo no 
observamos dicho efecto, sin embargo si coincide con la represión tanto en la actividad como a nivel transcripcional en ambos modelos (figura 6 y 7 ). La NADPH oxidasa suele ser usada por factores citotóxicos como el TGF-beta, quien la sobreactiva para producir ROS e inducir apoptosis (Sancho y Fabregat, 2011), en nuestros resultados se observa un decremento significativo inmediatamente a la aplicación del HGF, efecto que se sostiene a las $24 \mathrm{~h}$ y correlacionando con una mejora en sobrevivencia.

En conclusión, los resultados de la presente tesis muestran un efecto protector del HGF en células RINm5F, dicha consecuencia se relacionó con la activación de rutas de sobreviencia por el HGF como ERK1/2, la abrogación de rutas citotóxicas (p38) y de sistemas prooxidantes como la NADPH oxidasa, y la elevación de proteínas antioxidantes. 


\section{Referencias}

Aparicio I.M., Garcia-Marin L.J., Andreolotti A.G., Bodega G., Jensen R.T. and Bragado M.J. (2003). "Hepatocyte growth factor activates several transduction pathways in rat pancreatic acini." Biochim Biophys Acta 1643: 37-46.

Bedard, K. and K. H. Krause (2007). "The NOX family of ROS-generating NADPH oxidases: physiology and pathophysiology." Physiol Rev 87(1): 245-313.

Bertotti, A. and P. M. Comoglio (2003). "Tyrosine kinase signal specificity: lessons from the HGF receptor." Trends Biochem Sci 28(10): 527-533.

Bhardwaj, P. and R. K. Yadav (2013). "Chronic pancreatitis: role of oxidative stress and antioxidants." Free Radic Res 47(11): 941-949.

Bhopale, K. K., M. Falzon, G. A. Ansari and B. S. Kaphalia (2014). "Alcohol oxidizing enzymes and ethanol-induced cytotoxicity in rat pancreatic acinar AR42J cells." In Vitro Cell Dev Biol Anim 50(4): 373-380.

Binker, M. G. and L. I. Cosen-Binker (2014). "Acute pancreatitis: The stress factor." World J Gastroenterol 20(19): 5801-5807.

Black, M. H., R. M. Watanabe, E. Trigo, M. Takayanagi, J. M. Lawrence, T. A. Buchanan and A. H. Xiang (2013). "High-fat diet is associated with obesitymediated insulin resistance and beta-cell dysfunction in Mexican Americans." $\underline{\mathrm{J}}$ Nutr 143(4): 479-485.

Clavijo-Cornejo, D., C. Enriquez-Cortina, A. Lopez-Reyes, M. Dominguez-Perez, N. Nuno, M. Dominguez-Meraz, L. Bucio, V. Souza, V. M. Factor, S. S. Thorgeirsson, M. C. Gutierrez-Ruiz and L. E. Gomez-Quiroz (2013). "Biphasic 
regulation of the NADPH oxidase by HGF/c-Met signaling pathway in primary mouse hepatocytes." Biochimie 95(6): 1177-1184.

Chin, J. H. and D. B. Goldstein (1977). "Electron paramagnetic resonance studies of ethanol on membrane fluidity." Adv Exp Med Biol 85A: 111-122.

Dabrowski, A., S. J. Konturek, J. W. Konturek and A. Gabryelewicz (1999). "Role of oxidative stress in the pathogenesis of caerulein-induced acute pancreatitis." Eur J Pharmacol 377(1): 1-11.

Diaz-Rubio, J. L., A. Torre-Delgadillo and G. Robles-Diaz (2002). "[Diabetes mellitus in acute pancreatitis]." Rev Gastroenterol Mex 67(4): 278-284.

Edderkaoui, M., C. Nitsche, L. Zheng, S. J. Pandol, I. Gukovsky and A. S. Gukovskaya (2011). "NADPH oxidase activation in pancreatic cancer cells is mediated through Akt-dependent up-regulation of p22phox." J Biol Chem 286(10): 7779-7787.

Enriquez-Cortina, C., M. Almonte-Becerril, D. Clavijo-Cornejo, M. PalestinoDominguez, O. Bello-Monroy, N. Nuno, A. Lopez, L. Bucio, V. Souza, R. Hernandez-Pando, L. Munoz, M. C. Gutierrez-Ruiz and L. E. Gomez-Quiroz (2013). "Hepatocyte growth factor protects against isoniazid/rifampicin-induced oxidative liver damage." Toxicol Sci 135(1): 26-36.

Farfan Labonne, B. E., M. Gutierrez, L. E. Gomez-Quiroz, M. Konigsberg Fainstein, L. Bucio, V. Souza, O. Flores, V. Ortiz, E. Hernandez, D. Kershenobich and M. C. Gutierrez-Ruiz (2009). "Acetaldehyde-induced mitochondrial dysfunction sensitizes hepatocytes to oxidative damage." Cell Biol Toxicol 25(6): 599-609.

Fernandes, D. C., J. Wosniak, Jr., L. A. Pescatore, M. A. Bertoline, M. Liberman, F. R. Laurindo and C. X. Santos (2007). "Analysis of DHE-derived oxidation products 
by HPLC in the assessment of superoxide production and NADPH oxidase activity in vascular systems." Am J Physiol Cell Physiol 292(1): C413-422.

Fujimori, N., T. Oono, H. Igarashi, T. Ito, T. Nakamura, M. Uchida, D. H. Coy, R. T. Jensen and R. Takayanagi (2011). "Vasoactive intestinal peptide reduces oxidative stress in pancreatic acinar cells through the inhibition of NADPH oxidase." Peptides 32(10): 2067-2076.

Gomez-Quiroz, L., L. Bucio, V. Souza, C. Escobar, B. Farfan, E. Hernandez, M. Konigsberg, F. Vargas-Vorackova, D. Kershenobich and M. C. Gutierrez-Ruiz (2003). "Interleukin 8 response and oxidative stress in HepG2 cells treated with ethanol, acetaldehyde or lipopolysaccharide." Hepatol Res 26(2): 134-141.

Gomez-Quiroz, L. E., V. M. Factor, P. Kaposi-Novak, C. Coulouarn, E. A. Conner and S. S. Thorgeirsson (2008). "Hepatocyte-specific c-Met deletion disrupts redox

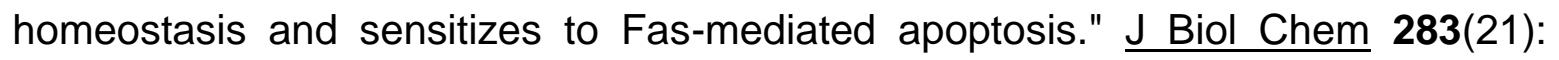
$14581-14589$.

Gomez-Quiroz, L. E., R. Paris, J. M. Lluis, L. Bucio, V. Souza, E. Hernandez, M. Gutierrez, M. Santiago, C. Garcia-Ruiz, J. C. Fernandez-Checa, D. Kershenobich and M. C. Gutierrez-Ruiz (2005). "Differential modulation of interleukin 8 by interleukin 4 and interleukin 10 in HepG2 cells treated with acetaldehyde." Liver Int 25(1): 122-130.

Huh, C. G., V. M. Factor, A. Sanchez, K. Uchida, E. A. Conner and S. S. Thorgeirsson (2004). "Hepatocyte growth factor/c-met signaling pathway is required for efficient liver regeneration and repair." Proc Natl Acad Sci U S A 101(13): 4477-4482. 
Kaposi-Novak, P., J. S. Lee, L. Gomez-Quiroz, C. Coulouarn, V. M. Factor and S. S. Thorgeirsson (2006). "Met-regulated expression signature defines a subset of human hepatocellular carcinomas with poor prognosis and aggressive phenotype." J Clin Invest 116(6): 1582-1595.

Koulajian, K., T. Desai, G. C. Liu, A. Ivovic, J. N. Patterson, C. Tang, J. El-Benna, J. W. Joseph, J. W. Scholey and A. Giacca (2013). "NADPH oxidase inhibition prevents beta cell dysfunction induced by prolonged elevation of oleate in rodents." Diabetologia 56(5): 1078-1087.

Lenzen, S. (2008). "Oxidative stress: the vulnerable beta-cell." Biochem Soc Trans 36(Pt 3): 343-347.

Leung, P. S. (2010). The Renin-Angiotensin System: Current Research Progress in The Pancreas, Advances in Experimental Medicine and Biology. Hong Kong, Springer Netherlands

Lin, H. H., H. Y. Chang, Y. T. Chiang, M. S. Wu, J. T. Lin and W. C. Liao (2014). "Smoking, Drinking and Pancreatitis: A Population-based Cohort Study in Taiwan." Pancreas.

Marquardt, J. U., D. Seo, L. E. Gomez-Quiroz, K. Uchida, M. C. Gillen, M. Kitade, P. Kaposi-Novak, E. A. Conner, V. M. Factor and S. S. Thorgeirsson (2012). "Loss of C-Met accelerates development of liver fibrosis in response to $\mathrm{CCl}(4)$ exposure through deregulation of multiple molecular pathways." Biochim Biophys Acta 1822(6): 942-951.

Murakami, T., T. Fujita, T. Taguchi, Y. Nonaka and K. Orita (1992). "The blood vascular bed of the human pancreas, with special reference to the insulo-acinar 
portal system. Scanning electron microscopy of corrosion casts." Arch Histol Cytol 55(4): 381-395.

Nakamura, T. and S. Mizuno (2010). "The discovery of hepatocyte growth factor (HGF) and its significance for cell biology, life sciences and clinical medicine." Proc Jpn Acad Ser B Phys Biol Sci 86(6): 588-610.

Park, M., D. Y. Song, Y. Je and J. E. Lee (2014). "Body mass index and biliary tract disease: A systematic review and meta-analysis of prospective studies." Prev Med 65C: 13-22.

Pocock, G. and C. D. Richards (2005). Fisiología Humana. La Base de la Medicina. Barcelona, MASSON.

Ryu, G. R., E. Lee, H. J. Chun, K. H. Yoon, S. H. Ko, Y. B. Ahn and K. H. Song (2013). "Oxidative stress plays a role in high glucose-induced activation of pancreatic stellate cells." Biochem Biophys Res Commun 439(2): 258-263.

Sancho, P. and I. Fabregat (2011). "The NADPH oxidase inhibitor VAS2870 impairs cell growth and enhances TGF-beta-induced apoptosis of liver tumor cells." Biochem Pharmacol 81(7): 917-924.

Seitz, H. K. and F. Stickel (2009). "Acetaldehyde as an underestimated risk factor for cancer development: role of genetics in ethanol metabolism." Genes Nutr 5(2): 121-128.

Seo, J. B., G. A. Gowda and D. S. Koh (2013). "Apoptotic damage of pancreatic ductal epithelia by alcohol and its rescue by an antioxidant." PLoS One 8(11): e81893.

Takami, T., P. Kaposi-Novak, K. Uchida, L. E. Gomez-Quiroz, E. A. Conner, V. M. Factor and S. S. Thorgeirsson (2007). "Loss of hepatocyte growth factor/c-Met 
signaling pathway accelerates early stages of $\mathrm{N}$-nitrosodiethylamine induced hepatocarcinogenesis." Cancer Res 67(20): 9844-9851.

Valdes-Arzate, A., A. Luna, L. Bucio, C. Licona, D. L. Clemens, V. Souza, E. Hernandez, D. Kershenobich, M. C. Gutierrez-Ruiz and L. E. Gomez-Quiroz (2009). "Hepatocyte growth factor protects hepatocytes against oxidative injury induced by ethanol metabolism." Free Radic Biol Med 47(4): 424-430.

Weaver, J. R. and D. A. Taylor-Fishwick (2013). "Regulation of NOX-1 expression in beta cells: a positive feedback loop involving the Src-kinase signaling pathway." Mol Cell Endocrinol 369(1-2): 35-41.

Xiping, Z., W. Dijiong, L. Jianfeng, C. Qihui, Y. Jing, J. Penghui, Y. Meijuan and Z. Ninni (2009). "Effects of Salvia miltiorrhizae on ICAM-1, TLR4, NF-kappaB and Bax proteins expression in multiple organs of rats with severe acute pancreatitis or obstructive jaundice." Inflammation 32(4): 218-232.

Yu, J. H., J. W. Lim, K. H. Kim, T. Morio and H. Kim (2005). "NADPH oxidase and apoptosis in cerulein-stimulated pancreatic acinar AR42J cells." Free Radic Biol Med 39(5): 590-602. 